\title{
Agomelatine in Depressive Disorders: Its Novel Mechanisms of Action
}

\author{
Venkataramanujan Srinivasan, Ph.D. \\ Rahimah Zakaria, M.B.B.S., Ph.D. \\ Zahiruddin Othman, M.D., M.Med. \\ (Psychiatry) \\ Edward C. Lauterbach, M.D. \\ Darío Acuña-Castroviejo, M.D., Ph.D.
}

Disruptions in sleep and sleep-wake cycle regulation have been identified as one of the main causes for the pathophysiology of depressive disorders. The search has been on for the identification of an ideal antidepressant that could improve both sleep disturbances and depressive symptomatology. Melatonin, the major hormone of the pineal gland, has been shown to improve sleep and is involved in the regulation of the sleep-wake cycle. Identification of high concentrations of $M T_{1}$ and $\mathrm{MT}_{2}$ melatonergic receptors in the suprachiasmatic nucleus of the anterior hypothalamus, the structure concerned with regulation of circadian rhythms and sleep-wake cycles, has led to the development of melatonergic agonists with greater potency and longer durations of action. Agomelatine is one such melatonergic agonist that acts specifically on $M T_{1} / M T_{2}$ melatonergic receptors and at the same time exhibits $5-\mathrm{HT}_{2 \mathrm{C}}$ antagonism, a property that is utilized by current antidepressants that are in clinical use. Agomelatine has been shown to be effective in a number of animal models of depression. Clinical studies undertaken on patients with major depression, bipolar disorders, seasonal affective disorder, and generalized anxiety disorder have all shown that agomelatine is also very effective in ameliorating depressive symptoms and manifesting early onset of action with a good tolerability and safety profile. It improved sleep efficiency and also resynchronized the disrupted circadian rhythms. Hence, the melatonergic modulation by agomelatine is suggested as one of the mechanisms for its antidepressant effect. Agomelatine's action on dendritic neurogenesis in animal models of depression is also identified as yet another action.

(The Journal of Neuropsychiatry and Clinical Neurosciences 2012; 24:290-308)

$\mathrm{D}$ epressive disorders constitute a heterogeneous group of disorders and involve complex interactions of genetic and environmental factors. Among the physiological factors that trigger this disease, disturbances of circadian and sleep-wake cycles, as well as abnormalities of melatonin secretion, have become the primary focus of attention ${ }^{1}$ and formed the basis for the development of effective pharmacotherapeutic agents for treating this disease. Pharmacotherapy for treatment of depressive disorders have been in use since the 1950s, and includes tricyclic antidepressants (TCAs), monoamine oxidase inhibitors (MAOIs), serotonin-norepinephrine

Received September 14, 2011; revised November 25, 2011; accepted December 12, 2011. From Sri Sathya Sai Medical Educational and Research Foundation, Prasanthi Nilayam, Kovai Thirunagar Coimmbatore641014, Tamilnadu, India (VS); the Dept. of Physiology (RZ), Dept. of Psychiatry (ZO), School of Medical Sciences, Universiti Sains Malaysia, Kota Bharu, Kelantan, Malaysia; the Dept. of Psychiatry, School of Medical Sciences, Universiti Sains Malaysia, Kota Bharu, Kelantan, Malaysia (ZO); the Depts. of Psychiatry and Interna Medicine (Neurology Section), Mercer University School of Medicine, Macon GA; the Instituto de Biotecnología, Centro de Investigación Biomédica, Parque Tecnológico de Ciencias de la Salud, Universidad de Granada, Granada, Spain (DA-C).

Copyright @ 2012 American Psychiatric Association 
reuptake inhibitors (SNRIs), and selective serotonin reuptake inhibitors (SSRIs). All these antidepressants act through manipulations of monoaminergic neurotransmitter pathways in the brain and have been effective in causing remission of depressive symptoms in most of the clinical trials undertaken. ${ }^{2-4}$ These drugs constitute the third most widely used class of antidepressants worldwide, with SSRIs alone accounting for $80 \%$ of the total market share. ${ }^{5}$ With intensive epidemiological and EEG studies identifying "sleep and sleep-wake disturbances" as the most important underlying factor for the pathophysiology of depressive disorders, ${ }^{6}$ the focus has shifted toward developing new classes of antidepressants that can correct the underlying abnormalities in sleep and circadian rhythms seen in patients with major depressive disorder (MDD) and bipolar disorders. Reports of significant correlations between low melatonin production and insomnia ${ }^{7-9}$ suggest the possible relationship between melatonin and sleep. Use of slow-release melatonin in patients with depressive disorders improved sleep quality, but exerted only weak antidepressant effects. ${ }^{10}$ Development of a new synthetic analog of melatonin, namely agomelatine, a specific agonist of $\mathrm{MT}_{1}$ and $\mathrm{MT}_{2}$ melatonin receptors and a selective antagonist to $5-\mathrm{HT}_{2} \mathrm{C}$ receptors, ${ }^{11}$ has been shown to have significant antidepressant properties. ${ }^{12}$ Following these findings, the antidepressant efficacy of agomelatine has been demonstrated in a number of clinical studies undertaken in Europe, and it has been supported by earlier review studies. ${ }^{13-17}$

\section{MELATONIN: ITS BIOSYNTHESIS AND METABOLISM}

Melatonin biosynthesis occurs mainly in the pineal gland of all vertebrates, with highest secretion occurring only during dark hours of the night, and its synthesis in the pineal gland is regulated by the suprachiasmatic nucleus $(\mathrm{SCN})$ of the hypothalamus. Environmental light, which acts as the major zeitgeber, synchronizes the pineal melatonin secretion with the 24 hours of the light-dark cycle. ${ }^{18}$ Besides the pineal gland, melatonin is also synthesized by other organs, such as the retina, ${ }_{1}^{19}$ gastrointestinal tract, ${ }^{20}$ skin, ${ }^{21}$ lymphocytes, ${ }^{22}$ thymus ${ }^{23}$ and many other areas in the body. However, circulating melatonin is derived mainly from the pineal gland. The biosynthetic pathway of melatonin is shown in Figure 1. Once formed, melatonin is released either into blood capillaries, or directly into the cerebrospinal fluid. ${ }^{24}$ Melatonin has a very short half-life of about 20 to 30 minutes. ${ }^{25}$ Circulating melatonin is metabolized in the liver by hepatic cytochrome P450 (CYP) mono-oxygenases, followed by conjugation to form 6-hydroxy-melatonin, which is the main urinary metabolite, aMT6s; but in neural tissues, the primary cleavage product is N1-acetyl-N2-formyl-5-methoxykynuramine (AFMK), which can be further decomposed to form N1-acetyl-5-methooxy-kynuramine (AMK). ${ }^{26}$

\section{MELATONIN RECEPTORS}

Except for its free-radical scavenging actions, all other physiological effects of melatonin in the body are attributed to the presence of specific membrane-bound $\mathrm{MT}_{1}$ and $\mathrm{MT}_{2}$ melatonin receptors, cytosol receptors, or nuclear receptors like RZR/ROR $\alpha$ orphan receptors. The two membrane-bound receptors, $\mathrm{MT}_{1}$ and $\mathrm{MT}_{2}$, are G-protein receptors and have been cloned and characterized. ${ }^{27,28} \mathrm{MT}_{1}$ receptor activation leads to adenylyl cyclase inhibition and phospholipase $C \beta$ activation. ${ }^{29}$ $\mathrm{MT}_{2}$ receptor activation leads to a number of signaltransduction pathways, like phosphoinositide production, inhibition of adenylyl cyclase, and inhibition of the guanylyl cyclase pathway. ${ }^{30}$

$\mathrm{MT}_{1}$ and $\mathrm{MT}_{2}$ melatonin receptors are expressed in various tissues of the body, either separately or together. Of these various sites, the presence of $\mathrm{MT}_{1}$ and $\mathrm{MT}_{2}$ melatonin receptors in the $\mathrm{SCN}$ is of functional importance for regulation of the sleep-wake cycle and, hence, for discussing the possible role of melatonergic receptors and melatonergic drugs used for the treatment of insomnia, circadian rhythm, and depressive disorders. ${ }^{31}$

\section{MELATONIN, DEPRESSIVE DISORDERS, AND SLEEP DISTURBANCES}

It is well known that patients with either major depressive disorder or bipolar disorders exhibit marked difficulties in the initiation and maintenance of sleep, poor quality of sleep, and frequent early-morning awakenings. ${ }^{32-34}$ Also, the temporal distribution of REM sleep is typically altered during overnight sleep in depression, and this abnormality in the timing of the $\mathrm{REM} /$ non-REM cycle is attributed to the disorganized nature of the pathways that regulate the sleep-wake cycle. $^{34}$ The National Institute of Mental Health (NIMH) Epidemiologic Catchment Area (ECA) study of sleep 


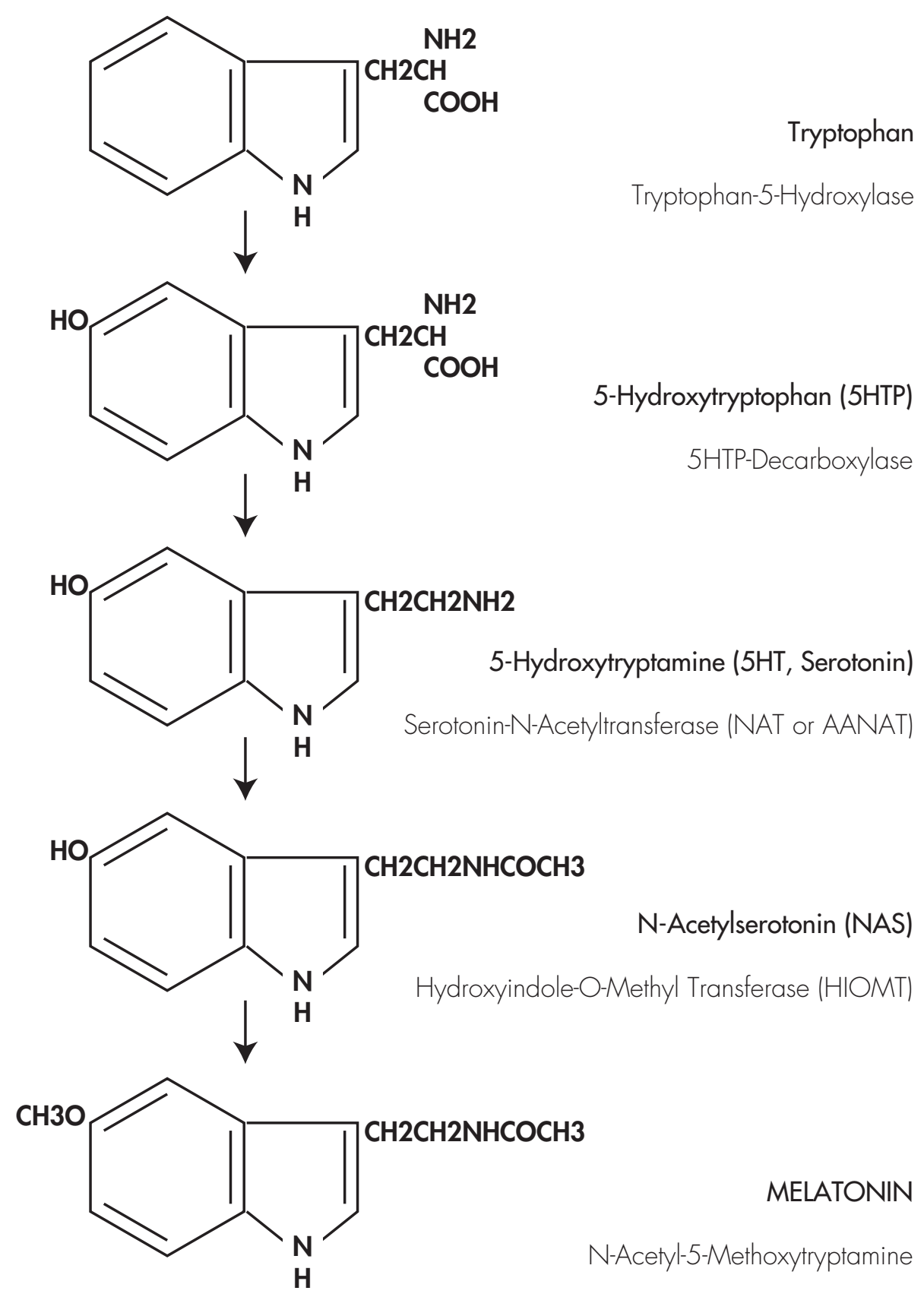

disturbances and psychiatric disorders has identified sleep disturbance as a highly significant risk factor for subsequent development of depression. ${ }^{35}$ Hence, persistent sleep abnormalities should be addressed first in treating depressive symptomatology. ${ }^{36,37}$ A comprehensive program of therapy for depressive disorders should depend not only on clinical and behavioral symptoms, but also on the sleep and circadian rhythm disturbances of depressive disorders. ${ }^{38,39}$ Accordingly, an ideal antidepressant should decrease sleep-onset latency, decrease the number of awakenings after sleep onset, and should increase alertness during daytime. ${ }^{40}$ Currently, SSRIs constitute $80 \%$ of all prescription antidepressants, but they have been found to exacerbate the sleep 
disturbances, and one-third of the patients receiving SSRIs also receive concomitant sedative-hypnotics. ${ }^{41}$ Use of these sedative-hypnotics, consisting of benzodiazepine or nonbenzodiazepine drugs, can also result in many adverse effects, such as rebound insomnia, cognitive and memory impairment, dependency, and so on. Also, all the conventional antidepressants that are in use today (TCAs, MAOIs, SNRIs, SSRIs) elevate daytime mood by activating CNS mechanisms. If these energizing effects are sustained at night, they can very much reduce sleep efficiency and quality. ${ }^{42}$ Hence, an ideal antidepressant, while elevating the mood during daytime, should also preserve the quality of sleep at night. ${ }^{43}$ Agomelatine, a melatonergic agonist developed by Servier Laboratories, France, with a high affinity for $\mathrm{MT}_{1}$ and $\mathrm{MT}_{2}$ melatonergic receptors, and antagonism of $5-\mathrm{HT}_{2 \mathrm{C}}$ receptors, has demonstrated its potential as an antidepressant in a number of preclinical studies and has also proved its clinical efficacy in patients with depressive disorders. This review will present the findings on agomelatine's actions in animal models of depression as well as its clinical efficacy in patients with depressive disorders.

\section{AGOMELATINE: CHEMISTRY AND PHARMACODYNAMICS}

Agomelatine has structural similarities to melatonin and is a napthalenic compound (Figure 2) chemically designated as $\mathrm{N}$-[2-(7-methoxynaphth-1-yl)ethyl]acetamide. Its molecular formula is $\mathrm{C}_{15} \mathrm{H}_{17} \mathrm{NO}_{2}{ }^{44}$ Agomelatine has a short half-life of about 2 hours in human beings. It is rapidly absorbed from the gastrointestinal tract and immediately transported to the liver, where it is metabolized by three CYP isoenzymes: CYPA1, CYPA2, and CYP2C9. Four metabolites of agomelatine, namely, 3-hydroxy-S20098, 3-hydroxy-7-methyl-S20098, 7-desmethyl-S20098, and dihydrodiol-S20098 have been identified. ${ }^{45}$ On the basis of receptor-binding studies with more than 80 receptors and enzymes, it was concluded that agomelatine demonstrates significant affinity to $\mathrm{MT}_{1}$ and $\mathrm{MT}_{2}$ receptors, with overall selectivity of $>100$-fold. ${ }^{46}$ Agomelatine exhibits antagonism to $5-\mathrm{HT}_{2 \mathrm{C}}$ and $5-\mathrm{HT}_{2 \mathrm{~B}}$ receptors. ${ }^{11,47}$ Agomelatine has no significant affinity to muscarinic, histaminergic, adrenergic, or dopaminergic receptors. ${ }^{11}$ Because agomelatine increased levels of dopamine only in the frontal cortex, but not in the nucleus accumbens or striatum, it is suggested that agomelatine exerts $5-\mathrm{HT}_{2 \mathrm{C}}$ antagonism on dopaminergic and noradrenergic cortico-limbic pathways. ${ }^{48}$

\section{AGOMELATINE'S ANTIDEPRESSANT EFFECTS: PRECLINICAL STUDIES}

Agomelatine has demonstrated its antidepressant activity in several animal models of depression, such as the forced swimming test, ${ }^{49}$ psychosocial stress model, ${ }^{50}$ learned-helplessness model, ${ }^{12}$ transgenic mouse mod$\mathrm{el}^{46,51}$ and chronic mild stress model. ${ }^{52}$ The antidepressant activity of agomelatine in various animal models of depression is summarized in Table 1. The forcedswimming model has been used for assessing the antidepressant activity of a number of drugs. In this test, rodents are forced to swim in a situation where they cannot escape, as a result of which they become immobile, floating in an upright posture. ${ }^{50}$ This is a validated test for antidepressant activity.

The acute administration of agomelatine either orally or intraperitoneally to rats or mice at $4 \mathrm{mg} / \mathrm{kg}$, $16 \mathrm{mg} / \mathrm{kg}$, or $32 \mathrm{mg} / \mathrm{kg}$ doses significantly decreased the duration of immobility in all the doses tested in rats. ${ }^{49}$ But in mice, only repeated doses of agomelatine induced antidepressant-like effects in the forced-swimming model. The mechanism of antidepressant effect seen in this study was attributed to $5-\mathrm{HT}_{2 \mathrm{C}}$ antagonism and to action on melatonin receptors. ${ }^{49}$ The sucrose-consumption test after mild stress is used as one of the animal models of depression. By using this animal model, it was shown that administration of agomelatine at $10 \mathrm{mg} / \mathrm{kg}$ or $50 \mathrm{mg} / \mathrm{kg}$ doses counteracted the stressinduced decrease in sucrose consumption. Agomelatine was found to be more potent than melatonin in this antidepressant model. The role of $\mathrm{MT}_{1}$ and $\mathrm{MT}_{2}$ melatonergic receptors in mediating the antidepressant effect was evaluated by concomitant administration of the $\mathrm{MT}_{1} / \mathrm{MT}_{2}$ receptor-antagonist S22153, which inhibited the antidepressant effect of both agomelatine and melatonin and suggested the involvement of $\mathrm{MT}_{1} /$ $\mathrm{MT}_{2}$ melatonergic receptors in mediating the antidepressant response. ${ }^{51,52}$ In the learned-helplessness model test, the number of escape failures is evaluated to assess antidepressant efficacy. By using this model, the effects of agomelatine, imipramine, melatonin, and a selective $5-\mathrm{HT}_{2 \mathrm{C}}$ antagonist were evaluated, and the effects of agomelatine were compared with other agents. Agomelatine $(10 \mathrm{mg} / \mathrm{kg} \mathrm{BW})$ was given for 5 days once or twice daily, and the effects of pretreatment with S22153 (a melatonin-receptor antagonist; $20 \mathrm{mg} / \mathrm{kg} \mathrm{BW}$ ) were studied. A deficit in avoidance-learning was observed, 
FIGURE 2. Agomelatine, Melatonin, and Ramelteon

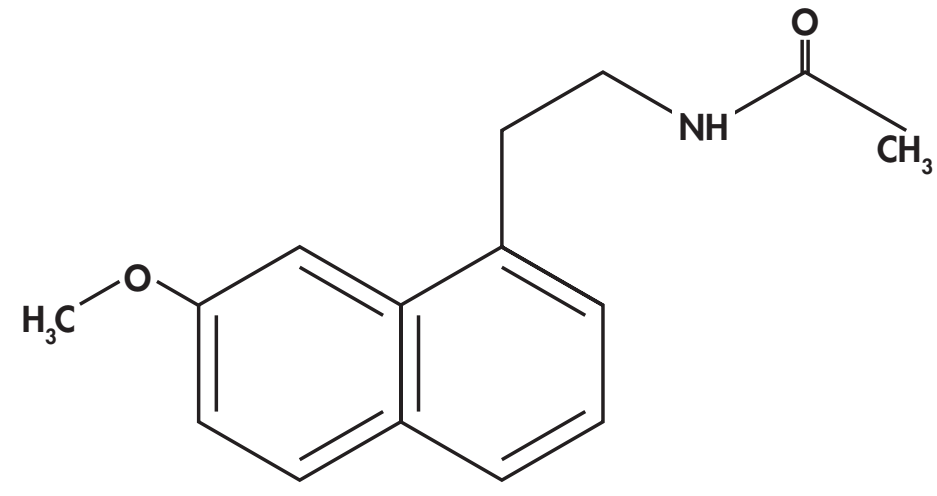

Agomelatine

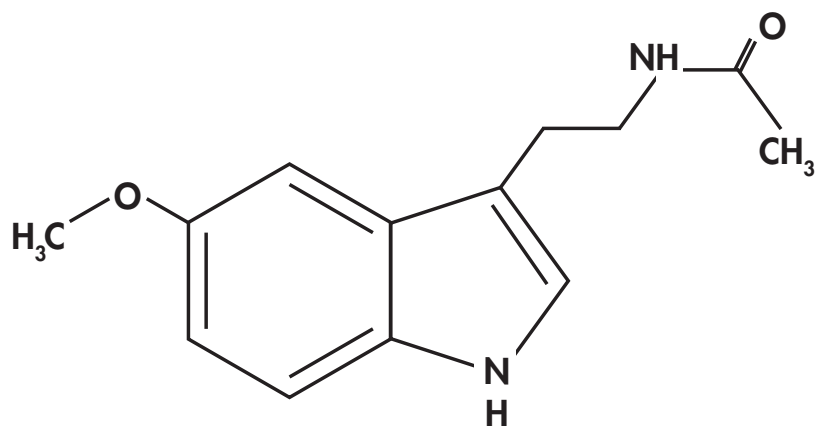

Melatonin

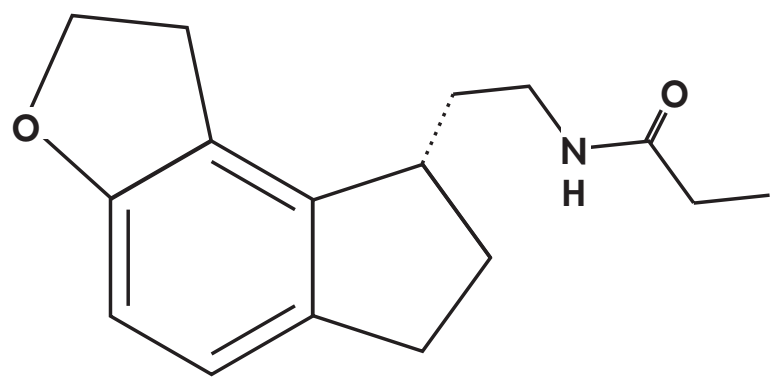

Ramelteon but administration of agomelatine alone $(10 \mathrm{mg} / \mathrm{kg} /$ BW) administered once a day significantly reduced this deficit. Because the effects of agomelatine were canceled by $\mathrm{S} 22153$ and not by SB-242084 (the $5-\mathrm{HT}_{2 \mathrm{C}}$ receptor antagonist), it is suggested that melatonin receptors are involved in the mediation of agomelatine's antidepressant effect. ${ }^{53,54}$

The transgenic mouse model with decreased glucocorticoid receptor (GR) expression is used for studying the antidepressant effects of drugs. Behavioral changes using the Porsolt forced-swim test and elevated plus-maze test were assessed in transgenic mice after administration of either agomelatine $10 \mathrm{mg} / \mathrm{kg}$, melatonin $10 \mathrm{mg} / \mathrm{kg}$, or desipramine $10 \mathrm{mg} / \mathrm{kg}$. Drugs were injected intraperitoneally for the total period of 21 to 42 days, 2 hours before the onset of the dark period. Agomelatine reversed the decreased mobility in the forced-swimming test, and the same effect was noted with melatonin or desipramine.
Even in the elevated plus-maze test, agomelatine reversed the behavioral changes. ${ }^{51}$ The number of openarm entries and total time spent were greatly reduced by agomelatine. In the same study, it was also noted that, after a phase-shift, agomelatine accelerated the phaseshift much more efficiently than melatonin, thereby showing its efficient resynchronizing effect, which indicates the therapeutic efficacy of agomelatine in treating depressive disorders. ${ }^{51}$

Depression is suggested to be due to desynchronization of various bodily rhythms, and correcting this underlying abnormality is thought to be critically important in correcting this disorder. The resynchronizing effect of agomelatine on disturbed circadian rhythms in experimental animals has also been studied earlier, and the effects of agomelatine on re-entrainment of disturbed circadian rhythms as studied by various investigators are presented in Table $1 .{ }^{55-60}$ The effects 
TABLE 1. Agomelatine: Its Chronobiotic and Antidepressant Effects in Experimental Animals

\begin{tabular}{|c|c|c|c|c|c|c|}
\hline Type of Study & Animal & Agomelatine Dose (mg/kg) & Comparison With Other Drugs & N Animals & Agomelatine Effect & References \\
\hline Animal model & $\begin{array}{l}\text { Long-Evans } \\
\text { rats }\end{array}$ & $1 \mathrm{mg}$ and $3 \mathrm{mg} / \mathrm{kg}$ & Melatonin $1 \mathrm{mg} / \mathrm{kg}$ & 24 & Phase-advanced the activity & $\begin{array}{l}\text { Armstrong et al., } \\
1993^{56}\end{array}$ \\
\hline Animal model & Rats & $1 \mathrm{mg} / \mathrm{kg}-100 \mathrm{mg} / \mathrm{kg}$ & Melatonin & Unspecified & Altered rat activity rhythms & $\underset{1995^{55}}{\text { Redman al., }}$ \\
\hline Animal model & $\begin{array}{l}\text { Long-Evans } \\
\text { rats }\end{array}$ & $0.5 \mathrm{mg} \cdot \mathrm{kg}-10 \mathrm{mg} / \mathrm{kg}$ & Melatonin $8 \mathrm{mg} / \mathrm{kg}$ & 106 & $\begin{array}{l}\text { Re-entrained free running } \\
\text { rhythms }\end{array}$ & $\begin{array}{l}\text { Martinet et al., } \\
1996^{57}\end{array}$ \\
\hline Animal model & $\begin{array}{l}\text { Long-Evans } \\
\text { hooded rats }\end{array}$ & $1 \mathrm{mg} / \mathrm{kg}-10 \mathrm{mg} / \mathrm{kg}$ & - & 52 & Entrainment of circadian rhythms & $\begin{array}{l}\text { Redman \& } \\
\text { Francis, } 1998^{58}\end{array}$ \\
\hline Animal model & $\begin{array}{l}\text { Long-Evans } \\
\text { rats }\end{array}$ & $50 \mu \mathrm{g} / \mathrm{kg}$ and $100 \mu \mathrm{g} / \mathrm{kg}$ & $\begin{array}{l}\text { Melatonin } 50 \mu \mathrm{g} / \mathrm{kg} \text { and } 100 \\
\mu \mathrm{g} / \mathrm{kg}\end{array}$ & 110 & Entrained free running rhythms & $\begin{array}{l}\text { Pitrosky et al., } \\
1999^{59}\end{array}$ \\
\hline Animal model & $\begin{array}{l}\text { Golden } \\
\text { hamsters }\end{array}$ & $20 \mathrm{mg} / \mathrm{kg}$ & - & 24 & $\begin{array}{l}\text { Accelerated resynchronization } \\
\text { of circadian rhythms by } 25 \%\end{array}$ & $\begin{array}{l}\text { Weibel et al., } \\
2000^{60}\end{array}$ \\
\hline $\begin{array}{l}\text { Chronic mild } \\
\text { stress }\end{array}$ & $\begin{array}{l}\text { Male Wistar } \\
\text { rats }\end{array}$ & $10 \mathrm{mg} / \mathrm{kg}-50 \mathrm{mg} / \mathrm{kg}$ & _ & - & $\begin{array}{l}\text { Reversed induced sucrose } \\
\text { consumption test } \\
\text { (antidepressant effect) }\end{array}$ & Papp et al., $2003^{52}$ \\
\hline $\begin{array}{l}\text { Forced- } \\
\text { swimming test }\end{array}$ & Rats and mice & - & $\begin{array}{l}\text { Melatonin } 4 \mathrm{mg} / \mathrm{kg}, 8 \mathrm{mg} / \mathrm{kg} \text {, } \\
16 \mathrm{mg} / \mathrm{kg}, 32 \mathrm{mg} / \mathrm{kg} \text {, and } \\
\quad 64 \mathrm{mg} / \mathrm{kg}\end{array}$ & $\begin{array}{l}10 \text { mice per group; } \\
4 \text { and } 6 \text { rats per } \\
\text { group }\end{array}$ & $\begin{array}{l}\text { Decreased duration of immobility } \\
\text { (antidepressant effect) }\end{array}$ & $\begin{array}{l}\text { Bourin et al., } \\
2004^{49}\end{array}$ \\
\hline $\begin{array}{l}\text { Animal model of } \\
\text { depression }\end{array}$ & $\begin{array}{l}\text { Transgenic } \\
\text { mice }\end{array}$ & $10 \mathrm{mg} / \mathrm{kg}$ & $\begin{array}{l}\text { Melatonin } 10 \mathrm{mg} / \mathrm{kg} ; \\
\quad \text { desipramine } 10 \mathrm{mg} / \mathrm{kg}\end{array}$ & 185 & $\begin{array}{l}\text { Effective in reversing transgenic } \\
\text { mouse behavioral changes (all } \\
\text { three drugs) }\end{array}$ & $\begin{array}{l}\text { Barden et al., } \\
2005^{51}\end{array}$ \\
\hline $\begin{array}{l}\text { Animal model of } \\
\text { depression }\end{array}$ & Wistar rats & $10 \mathrm{mg} / \mathrm{kg}$ and $30 \mathrm{mg} / \mathrm{kg}$ & $\begin{array}{l}\text { Melatonin } 3 \mathrm{mg} / \mathrm{kg} \text { and } 10 \\
\mathrm{mg} / \mathrm{kg} \text {; fluvoxamine } 4 \mathrm{mg} / \mathrm{kg}\end{array}$ & 10 per group & $\begin{array}{l}\text { Increased number of choices of } \\
\text { large, delayed reward } \\
\text { (antidepressant effect) }\end{array}$ & $\begin{array}{l}\text { Loiseau et al., } \\
2005^{63}\end{array}$ \\
\hline $\begin{array}{l}\text { Animal model of } \\
\text { depression }\end{array}$ & Wistar rats & $\begin{array}{l}2 \mathrm{mg} / \mathrm{kg}, 10 \mathrm{mg} / \mathrm{kg}, 50 \mathrm{mg} / \\
\mathrm{kg} \text {, and } 100 \mathrm{mg} / \mathrm{kg}\end{array}$ & $\begin{array}{l}\text { Melatonin } 2 \mathrm{mg} / \mathrm{kg}, 10 \mathrm{mg} / \mathrm{kg} \text {, } \\
\text { and } 50 \mathrm{mg} / \mathrm{kg}\end{array}$ & 40 per group & $\begin{array}{l}\text { Pretreatment with agomelatine } \\
\text { decreased number of escape } \\
\text { failures and exerted } \\
\text { antidepressant effect }\end{array}$ & $\begin{array}{l}\text { Bertaina-Anglade } \\
\text { et al., } 2006^{54}\end{array}$ \\
\hline $\begin{array}{l}\text { Animal model of } \\
\text { depression }\end{array}$ & Adult mice & $10 \mathrm{mg} / \mathrm{kg}$ or $40 \mathrm{mg} / \mathrm{kg}$ & Fluoxetine $18 \mathrm{mg} /$ day & 5 per group & $\begin{array}{l}\text { Both agomelatine and fluoxetine } \\
\text { increased swimming duration, } \\
\text { antidepressant-like effect } \\
\text { Agomelatine at both doses } \\
\text { increased home cage activity } \\
\text { and ratio of night over day; } \\
\text { normalized the disturbances of } \\
\text { circadian rhythms } \\
\text { At both doses of agomelatine, } \\
\text { increased the number of DCX+ } \\
\text { cells both in dorsal and ventral } \\
\text { hippocampal regions, an index } \\
\text { of antidepressant action }\end{array}$ & $\begin{array}{l}\text { Rainer et al., } \\
2011^{64}\end{array}$ \\
\hline
\end{tabular}


of agomelatine in resynchronizing disturbed circadian rhythms are attributed to its actions on $\mathrm{MT}_{1}$ and $\mathrm{MT}_{2}$ melatonin receptors present in the SCN. This chronobiotic property of agomelatine is regarded as one of the main underlying factors in the antidepressant effects of agomelatine. $^{61}$

Chronic social stress is one of the main triggering factors for the development of depressive disorders. On this basis, an animal model has been developed using tree shrews. Subordinate animals were subjected to psychosocial conflict daily by exposing them to dominant animals for 1 hour. The intensity of psychosocial stress in subordinate tree shrews was demonstrated by pronounced elevation of urinary cortisol levels, which reflects the sustained activation of the hypothalamicpituitary-adrenal (HPA) axis. Chronically stressed tree shrews were injected with agomelatine $40 \mathrm{mg} / \mathrm{kg}$ for 28 days. Agomelatine treatment allowed subordinate animals to remain under psychosocial conflict situations without stress and normalized the activity of the HPA axis, as shown by the reduction of urinary cortisol levels. ${ }^{62}$ By using impulse-related behavior, rats were trained in a T-maze and allowed to choose between two magnitudes of reward: immediate but small reward (getting two pellets) versus delayed but large reward (getting 10 pellets). The behavior of the rats was observed after administration of agomelatine $(10 \mathrm{mg} / \mathrm{kg}$ and $30 \mathrm{mg} / \mathrm{kg}$ doses), melatonin $3 \mathrm{mg} / \mathrm{kg}$ and $10 \mathrm{mg} / \mathrm{kg}$ doses, clomipramine $8 \mathrm{mg} / \mathrm{kg}$, fluvoxamine $4 \mathrm{mg} / \mathrm{kg}$, and GR205171 (substance P receptor antagonist) $10 \mathrm{mg} / \mathrm{kg}$ and $30 \mathrm{mg} / \mathrm{kg}$. Agomelatine, clomipramine, fluvoxamine, and GR205171 significantly increased the number of choices of the large-but-delayed reward. This delayedgratification response chosen by those with agomelatine and other drugs reveals their ability to improve impulsecontrol, regarded as an antidepressant effect. ${ }^{63}$ By using the chronic corticosterone animal model of depression and anxiety state (CCAMD), the behavioral consequences of either chronic agomelatine $(10 \mathrm{mg} / \mathrm{kg}-40 \mathrm{mg} / \mathrm{kg}$ per day) or fluoxetine (18 $\mathrm{mg} / \mathrm{kg}$ per day) were assessed in a number of paradigms such as the forced-swimming test, open-field paradigm, novelty-suppressed feeding (NSF), and the splash test (ST). Also, the effects of agomelatine on neurogenesis in the ventral and dorsal hippocampal regions were analyzed. Both agomelatine and fluoxetine were administered for a period of 4 weeks. Results of this study from the forced-swimming test, a well-recognized screening test for depression, shows that agomelatine at both doses $(10 \mathrm{mg} / \mathrm{kg}$ and 40 $\mathrm{mg} / \mathrm{kg}$ per day) and fluoxetine increased mobility duration in corticosterone- and noncorticosteronetreated rats. All multiple behavioral parameters with agomelatine and fluoxetine were found effective in reversing depression/anxiety-like phenotypes induced by excess glucocorticoids. ${ }^{64}$ The effect of agomelatine also was assessed on dorsal and ventral hippocampal regions. The ventral hippocampal region is implicated in anxiety and mood regulation, ${ }^{65,66}$ whereas the dorsal hippocampus is concerned with spatial memory. Assessment of the effects of agomelatine or fluoxetine on neurogenesis of dorsal and ventral hippocampal regions revealed that cell proliferations in corticosterone-treated rats were similar in both dorsal and ventral hippocampal regions. ${ }^{64}$ Agomelatine was able to reverse the decreased cell-proliferation induced by corticosterone in the whole hippocampal region. Besides these effects, agomelatine increased the light/ dark ratio and reversed the alterations in this ratio induced by corticosterone treatment, suggesting the normalization of disturbed circadian rhythms. Thus, all the parameters assessed in this study including antidepressant effect, normalization of disturbed circadian rhythms, and neurogenesis of hippocampal regions strongly suggest agomelatine as a new, innovative, antidepressant drug. ${ }^{67}$

\section{AGOMELATINE'S THERAPEUTIC EFFICACY IN DEPRESSIVE AND ANXIETY DISORDERS}

The first report on the clinical efficacy of agomelatine in the treatment of MDD was undertaken by Loo and his associates (2002). ${ }^{14}$ The report is based on the clinical trials undertaken in multi-national, multi-center, doubleblind, placebo-controlled investigations involving 711 patients drawn from 102 clinical centers in Belgium, the U.K., and France. Of these 711 patients, 67.1\% met the Diagnostic and Statistical Manual of Mental Disorders (DSM-IV) criteria for recurrent MDD, with $33.5 \%$ of patients having an episode of severe intensity. The mean baseline score on the 17-item Hamilton Rating Scale for Depression (Ham-D) was 27.4. Either agomelatine (25 $\mathrm{mg} /$ day) or paroxetine (20 mg/day) was administered for a total period of 8 weeks. By using remission analysis, the authors found that both agomelatine $(30.4 \%)$ and paroxetine $(25.7 \%)$ brought about significant remission when compared with placebo. Responder analysis (defined as $50 \%$-or-more reduction in the baseline score of the Ham-D) showed agomelatine to be superior (61.5\%) to placebo $(46.3 \%)$, whereas paroxetine did not differ 
much (56.3\%) from the placebo response. Among the 711 patients, a subpopulation of patients was categorized as severely depressed (586 patients with Ham-D score $>25$ ). Administration of agomelatine in this subpopulation produced a significant response, as compared with placebo $(p<0.05)$, whereas the paroxetine response did not differ much from the placebo effect. In addition to its effects on depressive symptoms, both agomelatine and paroxetine reduced anxiety symptoms. Similar to the findings reported from the above study, a second multi-center and multi-national study involving 21 centers across Finland, Canada, and South Africa, involving 212 patients (age 18-65 years) evaluated the clinical efficacy of agomelatine. ${ }^{68}$ In this study, the Ham-D score exceeded 22. This double-blind, placebo-controlled trial of agomelatine ( $25 \mathrm{mg}$ to $50 \mathrm{mg}$ ) was carried out for 6 weeks. In this study, the intent-to-treat (ITT) group consisted of 106 patients. Treatment with agomelatine for 6 weeks was associated with significant improvement in the clinical status of the patients $(\mathrm{p}=0.045)$ as compared with the placebo response. Agomelatine ( $25 \mathrm{mg}$ to $50 \mathrm{mg}$ ) reduced the Ham-D score quite significantly in the severely depressed subgroup with Ham-D scores exceeding 25. In this group, the agomelatine response was more effective than placebo $(\mathrm{p}=0.024)$. The significantly higher rate of responders to agomelatine $(49.1 \%)$ versus placebo $(34.3 \%)$ and the shorter time to first clinical response further lend support to the view that agomelatine is effective especially in patients with greater symptom severity.

The availability of antidepressants with efficacy in severely depressed patients is very important from the clinical point of view because this group is relatively resistant to current antidepressant therapy, which relies heavily on SNRIs or SSRIs. ${ }^{69}$ Hence, it is suggested that the greater clinical response seen with agomelatine when compared with that of other antidepressants (SSRIs) points to the superior efficacy of agomelatine over these other antidepressants. In another study, carried out for 12 weeks in 277 subjects, the patients were randomized to receive agomelatine at a dose of $50 \mathrm{mg} /$ day or venlafaxine XR (extended release) at two different doses, namely, $75 \mathrm{mg} /$ day for the first 2 weeks and then increased to $150 \mathrm{mg}$. The rates of remission were found to be $73 \%$ for agomelatine and $67 \%$ for venlafaxine-XRtreated patients. In a flexible-dosing, 6-week trial in 167 patients, subjects were assigned to receive either agomelatine ( $25 \mathrm{mg}-50 \mathrm{mg}$ ) or venlafaxine ( $75 \mathrm{mg}-150 \mathrm{mg}$ ) in the immediate-release form. A significant reduction in Ham-D scores was found in both groups, with agomelatine reducing the Ham-D score from 25.9 (SD: 3.2) to 9.0 (SD: 5.4), and venlafaxine reducing the Ham-D score from 26.0 (SD: 3.3 ) to 8.9 (SD: 5.2); the response rates were, respectively, $76 \%$ and $71 \%$ for agomelatine and venlafaxine immediate-release. ${ }^{15,70}$ To evaluate the sleep efficacy of agomelatine, a placebo-controlled, doubleblind study was undertaken in 332 patients with MDD for a period of 6 weeks. Agomelatine was administered at a dose of $25 \mathrm{mg}-50 \mathrm{mg} /$ day, and venlafaxine was given at a dose of $75 \mathrm{mg}-150 \mathrm{mg} /$ day. Although sleep quality, as measured by the Leeds Sleep Evaluation Questionnaire (LSEQ), was found better with agomelatine, the antidepressant effect was found similar for both drugs. ${ }^{67}$

Agomelatine's superiority in treating patients with MDD was studied in another 6-week, double-blind, parallel-group study, involving 238 patients. ${ }^{13}$ Agomelatine was administered at $25 \mathrm{mg} /$ day to these patients, and this dose was raised to $50 \mathrm{mg} /$ day after 2 weeks in patients who showed negligible improvement. Agomelatine was found to be significantly $(\mathrm{p}<0.001)$ superior to placebo, with a difference of 3.44. The response rate was $54.3 \%$ (agomelatine) to $35.5 \%$ (placebo). Agomelatine improved depressed mood and sleep items of the Ham-D score quite considerably. The drug was well tolerated and found to be safe in these patients. ${ }^{13}$

Evaluation of the efficacy of agomelatine on depressive symptoms in patients with major depressive disorder was carried out in an open-label study of 30 MDD patients receiving flexible doses of $25 \mathrm{mg}-50 \mathrm{mg} /$ day. Of these, only 24 patients $(80 \%)$ completed 8 weeks of treatment. Agomelatine treatment produced an early response, and significant improvement was noted in all these patients, as seen in Ham-D scores. Moreover, the effect of agomelatine in improving anhedonia was noted for the first time in this study. ${ }^{71}$

The efficacy of agomelatine in preventing the relapse of depressive symptoms and improving the clinical status of patients with MDD was assessed in a 32-week study on 165 patients. In this study, patients with DSM-IV major depressive disorder who responded to 8- to 10week administration of agomelatine ( $25 \mathrm{mg}-50 \mathrm{mg} /$ day) were randomly assigned to receive continuation of treatment with agomelatine $(\mathrm{N}=165)$ or placebo $(\mathrm{N}=174)$ for the treatment period of 24 weeks. The main outcome was time-to-relapse. During this 6-month evaluation period, the incidence of relapse was found to be significantly lower in patients who continued their treatment with agomelatine than those who switched over to placebo $(p=0.0001)$. The cumulative relapse rate with agomelatine 
was $21.7 \%$; and for placebo, it was $46.6 \%$. The findings of this study support the concept that agomelatine is an effective and safe antidepressant for continuation therapy. This long-term study confirms the earlier reports of agomelatine's efficacy for short-term therapy. ${ }^{13}$

Agomelatine $25 \mathrm{mg}$ /day was also used as an adjunctive treatment along with either lithium $(\mathrm{N}=14)$ or valpromide $(\mathrm{N}=7)$ in an open-label study of bipolar I patients. Agomelatine was administered for a minimum period of 6 weeks, followed by optimal extension up to an additional 46 weeks. Using intent-to-treat data, it was found that $81 \%$ of the patients met the criteria for marked improvement. Patients belonging to the severe category of depression, with Ham-D score over 25.2 (47.6\% of the total number of patients), responded as early as the first week of treatment. Nineteen patients entered the optional extension for a mean of 211 days (6-325 days), and, of these, 11 patients completed a 1 -year extension of treatment. Agomelatine was found to be an effective antidepressant in this study. ${ }^{72}$ (See Table 2 for a listing of studies on depression treatment.)

Besides being effective in treating MDD and bipolar I disorder, agomelatine also has been tried for depressed patients with seasonal affective disorder (SAD). In this open-label study the efficacy of agomelatine $(25 \mathrm{mg} /$ day) was evaluated for a period of 14 weeks. Assessment of agomelatine's efficacy was evaluated by using various psychometric scales, including the Structured Interview Guide for the Hamilton Depression Rating Scale (SAD version; SIGH-SAD); the Clinical Global Impression of Severity (CGI-S); the Clinical Global Impression of Improvement (CGI-I); the Circascreen, a self-rating scale for the assessment of sleep and circadian-rhythm disorders; and the Hypomania Scale. Agomelatine use in these patients caused a progressive and statistically significant decrease in SIGH-SAD, CGI-S, and CGI-I scores beginning in the second week of treatment. Also, the scores on the Circascreen improved quite substantially after agomelatine $(\mathrm{p}<0.001)$. Treatment with agomelatine for 14 weeks yielded a response rate of $75.7 \%$ (defined as a SIGH-SAD score $<50 \%$ of the baseline value) and a remission rate (SIGH-SAD $<8$ ) of $70.3 \%$ in the intent-to-treat sample. The efficacy of agomelatine in treating patients with seasonal affective disorder was demonstrated in this study. The drug was well tolerated throughout the study, and there was only

TABLE 2. Antidepressant Effects of Agomelatine: Clinical Studies

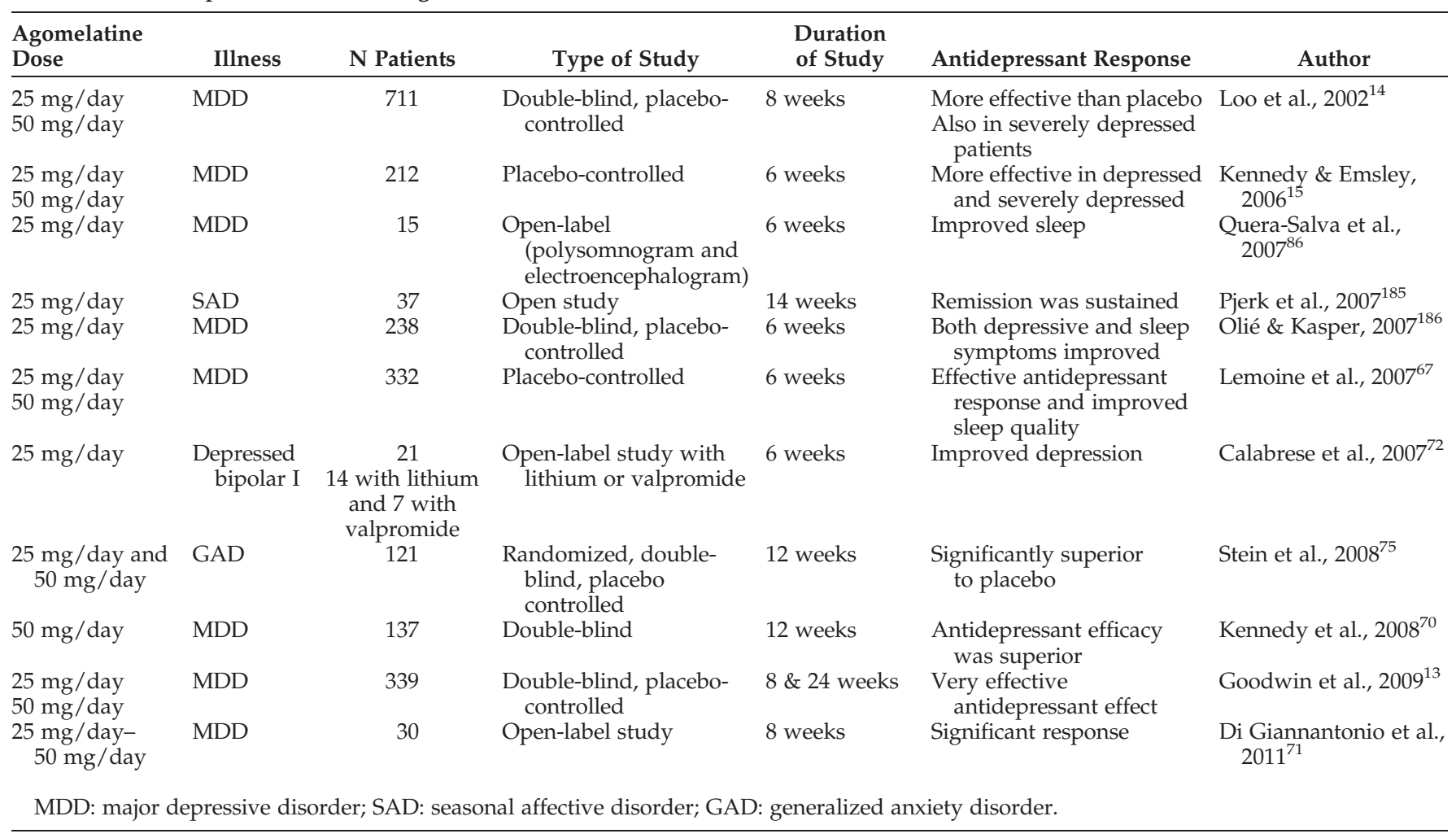


one report of an adverse effect, mild fatigue, showing thereby that the overall rating of agomelatine is good. ${ }^{73}$

Agomelatine has been found effective not only in animal models of depression but also in animal models of anxiety. ${ }^{16,74}$ The clinical efficacy of agomelatine has also been studied in 121 DSM-IV GAD patients randomized to agomelatine ( $25 \mathrm{mg}-50 \mathrm{mg} /$ day) or placebo for 12 weeks. Analysis of covariance of change in the last Hamilton Rating Scale for Anxiety (Ham-A) score from the baseline score demonstrated significant superiority of agomelatine in a $25 \mathrm{mg}-50 \mathrm{mg} /$ day dose, as compared with placebo. From this finding, it was concluded that agomelatine is an effective therapeutic drug for the treatment of generalized anxiety disorder. ${ }^{75}$

\section{AGOMELATINE IN OTHER DISORDERS}

Recently, agomelatine has been used in some other disorders, such as migraine and familial insomnia in a study conducted on 20 patients, age $23-45$ years, with migraine. Agomelatine use, in a 25-mg dose for 3 months, decreased migraine attacks effectively and also reduced depression severity, with normalization of night sleep. ${ }^{76}$ In yet another study in a patient with fatal familial insomnia (FFI), agomelatine in a 25-mg dose improved slow sleep and sleep efficiency. ${ }^{77}$

\section{SAFETY AND TOLERABILITY OF AGOMELATINE}

Agomelatine exhibits an excellent safety and tolerability record when compared with other antidepressants currently in use. Its safety record is close to that of placebo (5.9\% versus 3.5\%). The frequency of adverse effects such as headache, anxiety, abdominal pain, and diarrhea were less than that of placebo. The discontinuation rate for adverse effects with agomelatine was $8.0 \%$, which was close to that of placebo, $6.55 \%$, showing thereby the excellent tolerability record of agomelatine. ${ }^{14}$ Emergent adverse events such as gastrointestinal, cardiovascular, and body weight problems were generally lower than that of vanlafaxine or sertraline. ${ }^{78}$ Most of the currently available antidepressants induce sexual dysfunction that often interferes with recovery from the depressive episode. ${ }^{79}$ All antidepressants affect most phases of sexual activity, such as desire, arousal, and ejaculation in men. ${ }^{44}$ In studies on agomelatine-treated patients, only a few reports of sexual dysfunction have been documented. ${ }^{78,80}$

\section{AGOMELATINE'S ANTIDEPRESSANT EFFECT: MECHANISM OF ACTION}

It is a longstanding dictum that all available antidepressants exert their therapeutic actions mainly by the modulation of monoaminergic mechanisms in the brain. Depressive patients often experience a number of sleep disturbances, like difficulty in falling asleep, staying asleep, disturbed nocturnal sleep, early-morning awakening, etc. ${ }^{36}$ A number of studies point out that depression is linked to disturbances in circadian rhythms; hence, an antidepressant that benefits sleep quality and resets disturbed circadian rhythms will have more beneficial therapeutic antidepressant efficacy. As noted in the earlier sections, agomelatine is a melatonergic agonist of $\mathrm{MT}_{1} / \mathrm{MT}_{2}$ melatonergic receptors, with antagonism of $5-\mathrm{HT}_{2 \mathrm{C}}$ serotonergic receptors. The therapeutic efficacy of agomelatine in depressive disorders is attributed to its action on $\mathrm{MT}_{1}$ and $\mathrm{MT}_{2}$ melatonergic receptors, present largely in the SCN of the hypothalamus, and also to its $5-\mathrm{HT}_{2 \mathrm{C}}$ antagonism. ${ }^{54,81} 5-\mathrm{HT}_{2 \mathrm{C}}$ receptors are concentrated in the frontal cortex, amygdala, hippocampus, cortico-limbic structures, and SCN, and these structures are involved in the regulation of mood and cognition. ${ }^{82}$ Antidepressants in use have been shown to exert their therapeutic effects by decreasing the number of $5-\mathrm{HT}_{2 \mathrm{C}}$ receptors; ${ }^{83}$ but agomelatine's superiority over other antidepressants with $5-\mathrm{HT}_{2 \mathrm{C}}$ antagonism has been related to its effects in "improving sleep and daytime alertness." ${ }^{\prime 8,85}$ As we have seen earlier, agomelatine exerted a superior antidepressant effect in animal models of depression, whereas neither melatonin nor $5-\mathrm{HT}_{2 \mathrm{C}}$ antagonist antidepressants could mimic the antidepressant effect of agomelatine. ${ }^{54}$ Activation of both melatonergic $\mathrm{MT}_{1}$ and $\mathrm{MT}_{2}$ receptors and blockade of $5-\mathrm{HT}_{2 \mathrm{C}}$ receptors are essential for agomelatine's antidepressant effect. ${ }^{17}$ In patients with MDD, agomelatine has been shown to improve all aspects of the sleep-wake cycle as early as during the first week of treatment itself. ${ }^{86}$ This action of agomelatine in improving sleep efficiency and normalizing disturbed sleepwake cycles is an important mechanism by which agomelatine exerts its therapeutic antidepressant effect. ${ }^{39}$ Current antidepressants that are in clinical use today, especially SSRIs, cause profound sleep disturbances and exacerbate insomnia. Hence, sleep medications are used as a combination therapy along with antidepressants when treating patients with depressive 
disorders. As has been discussed earlier, all antidepressants elevate daytime mood in depressed patients by activating CNS arousal mechanisms, but since this effect is sustained throughout the 24-hour period, they can cause disruption of sleep mechanisms. ${ }^{42}$ The effectiveness of the novel antidepressant agomelatine is considered to be due to its dual actions of preserving sleep quality and efficiency through melatonergic $\mathrm{MT}_{1}$ and $\mathrm{MT}_{2}$ activation and elevating mood and activity through serotoninergic $5 \mathrm{HT}_{2 \mathrm{C}}$ antagonism. Agomelatine antagonizes the $5-\mathrm{HT}_{2 \mathrm{C}}$ receptors both during daytime and at night.

\section{CIRCADIAN PACEMAKER IN THE SUPRACHIASMATIC NUCLEI (SCN)}

All living organisms exhibit robust physiological and biochemical rhythms. ${ }^{87}$ These rhythms depend upon the presence of clock genes in the cells and are synchronized by a master clock located in the suprachiasmatic nuclei (SCN) of the hypothalamus. ${ }^{88}$ Circadian periodicity generated by the SCN is approximately 24.2 hours $^{89}$ and is synchronized to exactly 24 hours by the environmental light-dark cycle that acts through the retina and the retino-hypothalamic tract. ${ }^{90}$ Neurons in the SCN, as has been earlier noted, contain both $\mathrm{MT}_{1}$ and $\mathrm{MT}_{2}$ melatonin receptors. The circadian rhythm of melatonin secretion is regulated by the SCN, and melatonin is also a feedback regulator of the SCN by acting through both $\mathrm{MT}_{1}$ and $\mathrm{MT}_{2}$ melatonergic receptors. Both phase and amplitude of circadian rhythms are influenced by melatonin, acting through these receptors. Phaseshifting of circadian rhythms by melatonin are effected through $\mathrm{MT}_{2}$ melatonergic receptors, ${ }^{91,92}$ whereas the amplitude of circadian rhythms as studied by neuronal firing rates in SCN are influenced by melatonin acting through $\mathrm{MT}_{1}$ melatonergic receptors. ${ }^{93,94}$ As depressive disorders have been suggested to be due to disorders of circadian rhythms, including sleep-wake rhythms, it is likely that the actions of agomelatine in resetting the disturbed rhythms and sleep-wake rhythms is mediated through melatonergic receptors of the SCN.

The role of melatonin receptors in mediating antidepressant effects has been inferred from studies carried out on $\mathrm{MT}_{1}$ melatonin-receptor knockout mice $\left(\mathrm{MT}_{1}-/-\right)$. $\mathrm{MT}_{1}$ melatonin-receptor knockout mice exhibit depressionlike behavior. Both male and female melatonin-receptor knockout mice spent significantly more time in immobility in the forced-swimming test, a test that is usually employed for studying animal models of depression. ${ }^{86}$ Given that the disruptions in the circadian rhythms and sleep-wake cycles correlate with the severity of depression, ${ }^{85}$ the chronotherapeutic effect of agomelatine in MDD was evaluated. Agomelatine caused an increase in relative amplitude of the circadian rest-activity cycle by the end of Week 1, and it ran parallel with improvements of sleep efficiency and sleep latency from Week 1 to Week 6 . Depression and anxiety symptoms were very much improved in these patients, along with circadian rhythm and sleep improvements. ${ }^{75}$ This study supports the concept that agomelatine's specific target of action is mainly on $\mathrm{MT}_{1} / \mathrm{MT}_{2}$ melatonergic receptors in the $\mathrm{SCN}$, and, thereby, it corrects the underlying abnormality of the disturbed circadian rhythm and sleep-wake cycles of patients with depressive disorders. Hence, the important component of agomelatine's antidepressant effect resides in the mechanism of improving sleep efficiency coupled with the correction of disrupted circadian rhythms. ${ }^{95}$ Recent review studies have presented evidence supporting the clinical supremacy of agomelatine as an effective antidepressant, ${ }^{96}$ because of its early onset of action, ${ }^{97}$ low relapse rate, ${ }^{98}$ and targeting of melatonergic receptors for normalizing disturbed sleep and circadian rhythm. ${ }^{99-102}$

\section{NEUROGENIC EFFECTS OF AGOMELATINE: ANOTHER POSSIBLE MECHANISM FOR ITS ANTIDEPRESSANT EFFECT}

Recent preclinical studies have demonstrated that agomelatine, like other antidepressants, such as SSRIs and tricyclics, increase cell proliferation in the dentate gyrus of adult rats ${ }^{103,104}$ Chronic agomelatine treatment reversed the decreased neurogenesis of glucocorticoid receptor-impaired mice (GR-mice), an animal model of depression, ${ }^{105}$ and this effect was shown to occur mainly in the ventral hippocampus. ${ }^{103,104}$ The ventral hippocampus is implicated in anxiety and mood-regulation, and the dorsal hippocampus is concerned with spatial memory. ${ }^{65,66,106}$ Using corticosterone-treated mice (an animal model of depression and anxiety), the effects of agomelatine or fluoxetine were tested on dendritic maturation in both dorsal and ventral hippocampal regions. Although both antidepressants modified the maturation index, the number of double cortin expression cells (DCX+ cells) with tertiary dendrites was increased with agomelatine $(10 \mathrm{mg} / \mathrm{kg}-40$ $\mathrm{mg} / \mathrm{kg}$ day) only in the ventral hippocampal region of 
corticosterone-treated animals. ${ }^{64}$ Agomelatine induced an early acceleration of cell maturation at 8 days of development. ${ }^{104}$ Previous studies point out that the earliest time-point at which an antidepressant (fluoxetine) caused cell maturation was 21 days. ${ }^{107}$ From this study, it is evident that agomelatine has a more rapid action on cell maturation than SSRIs or any other monoaminergic antidepressants. ${ }^{104}$ Because agomelatine caused dendritic maturation in animal models of depression/anxiety, with earlier onset of action, and also demonstrated circadian-rhythm regulatory effects in animal models of depression, it contributes a distinctive profile in its antidepressant action. ${ }^{64}$ As the ventral hippocampus projects to the prefrontal cortex and amygdala, these agomelatine data support the view that the ventral hippocampus is involved in the emotional circuitry supporting the control of depressive/anxiety states. ${ }^{65,108}$ The ventral hippocampus seems to contain 5$\mathrm{HT}_{2 \mathrm{C}}$ receptors, but actions of agomelatine on dendritic maturation are thought to be mediated through both melatonergic and $5-\mathrm{HT}_{2 \mathrm{C}}$ receptors present in the ventral hippocampus. ${ }^{104}$ Hence, based on agomelatine's action in improving sleep efficiency, resynchronizing disrupted circadian rhythms, and enhancing dendritic maturation, demonstrated in both preclinical and clinical studies, it is clear that agomelatine has a novel antidepressant effect, with a rapid onset of action and greater clinical efficacy.

The effects of $25 \mathrm{mg} /$ day $-50 \mathrm{mg} /$ day of agomelatine ( $\mathrm{N}=154)$ or sertraline $(50 \mathrm{mg} /$ day-100 $\mathrm{mg} /$ day) was studied in patients with MDD over a period of 6 weeks in a randomized, double-blind study. With agomelatine, significant improvement in the relative amplitude of the rest-activity cycle was observed in the first week $(p=0.01)$; improvements in sleep quality $(p<0.001)$ and sleep efficiency $(p<0.001)$ were also observed from Week 1 to Week 6. Depressive symptoms improved considerably more with agomelatine $(p<0.05)$ than with sertraline. This study supports the idea that agomelatine is more efficient in improving sleep parameters, the circadian rest-activity cycle, and depressive symptoms than sertraline. ${ }^{109}$

\section{ADDITIONAL HEURISTIC MELATONERGIC ANTIDEPRESSANT AND ANXIOLYTIC MECHANISMS}

The effects of improved sleep and $\mathrm{MT}_{1} / \mathrm{MT}_{2}$ stimulation can also exert important effects on depressive and anxiogenic mechanisms that include oxidative stress, nitric oxide metabolism, mitochondrial function, neuroinflammation, neurotrophins (e.g., BDNF and GDNF), dopaminergic integrity, cyclic nucleotides (cAMP and cGMP), clock gene expression (Clock and NPAS2), heat shock proteins (HSP27), and apoptosis.

As mentioned above, sleep-enhancing effects may be important to agomelatine's therapeutic effects. More specifically, improvement of sleep may target certain mechanisms implicated in depressive and anxiety pathophysiology. Impaired sleep has been shown to adversely affect oxidative stress, ${ }^{110}$ mitochondrial integrity and function, ${ }^{111}$ and inflammation, ${ }^{112}$ mechanisms that play pathophysiological roles in mood and anxiety disorders. Specifically, oxidative stress has been related to major depression, ${ }^{113-117}$ especially with regard to the hippocampus. ${ }^{118}$ Oxidative stress has also been implicated in bipolar disorder ${ }^{119-125}$ and anxiety. ${ }^{126-128}$ Mitochondrial perturbations have been linked to major depression $^{114,129-131}$ and bipolar disorder. ${ }^{129,130,132}$ Inflammation has also been associated with major depression ${ }^{116,131,133-135}$ and bipolar disorder. ${ }^{132,136-138}$ For example, sleep deprivation is thought to trigger an inflammatory and stress response in the brain through gene induction. ${ }^{112}$ Improvement of sleep by agomelatine can therefore improve oxidative, mitochondrial, and inflammatory processes that contribute to the pathophysiology of these disorders.

Besides the SCN and several other hypothalamic regions, melatonin receptors can also be found in the paraventricular nucleus of the thalamus, parabrachial nuclei, and olfactory bulb in mice. ${ }^{139}$ In lizards, they are observed in visual pathway centers, the striatum, habenula, mammillary nucleus, septum, interpeduncular nucleus, medial cortex, and dorsal cortex. ${ }^{140}$ In rabbits, MT receptors were found in the cerebral cortex, cingulate gyrus, and hippocampus. ${ }^{141} \mathrm{MT}_{1}$ receptors are found in human cerebellar neurons. ${ }^{142} \mathrm{MT}_{2}$ receptors are distributed in the human hippocampus ${ }^{143}$ and cerebellar glia. ${ }^{142}$ Limbic structures, striatum, cerebellum, hippocampus, and cingulate gyrus have each been demonstrated to play important roles in human mood disorders. Effects on $\mathrm{MT}_{1}$ and $\mathrm{MT}_{2}$ receptors in these areas might therefore mediate the antidepressant and anxiolytic effects of agomelatine.

Direct agonist effects of agomelatine on melatonin $\mathrm{MT}_{1}$ and $\mathrm{MT}_{2}$ receptors may also remedy relevant pathophysiological processes by protecting against oxidative stress, including effects on nitric oxide (NO) levels. Protection against oxidative stress appears to be 
mediated through $\mathrm{MT}_{1}{ }^{144-147}$ and possibly, $\mathrm{MT}_{2}{ }^{146,147}$ receptors. NO is important in mediating major depression $^{148}$ and bipolar depression ${ }^{149}$ pathophysiologies. In bipolar depression, serum NO is elevated, and normalizes with antidepressant treatment over 30 days. ${ }^{149}$ In rat intestinal synaptosomes, melatonin reduced $\mathrm{NO}$ synthase activity, an effect possibly mediated by the $\mathrm{MT}_{1}$ receptor. ${ }^{150} \mathrm{MT}_{1}$ and $\mathrm{MT}_{2}$ receptor stimulation also independently increases brain-derived neurotrophic factor (BDNF). BDNF is involved in the pathophysiologies of both major depression ${ }^{151-153}$ and bipolar depression. ${ }^{154,155}$ Although stimulation of either $\mathrm{MT}_{1}$ or $\mathrm{MT}_{2}$ receptors increase BDNF concentrations, ${ }^{156}$ agomelatine additionally increases BDNF through a synergistic effect of $\mathrm{MT}_{1}, \mathrm{MT}_{2}$, and $5 \mathrm{HT}_{2 \mathrm{c}}$ receptors. ${ }^{104,157}$

As noted earlier, $\mathrm{MT}_{1}$ stimulation inhibits adenylyl cyclase cAMP production, ${ }^{158}$ consistent with cAMP down-regulation that has similarly been correlated with the antidepressant effects of salbutamol ${ }^{159}$ and imipramine. ${ }^{160} \mathrm{MT}_{1}$ receptor activity in particular has been correlated with neurotrophic increases in $\mathrm{BDNF}^{156,161}$ glial-derived neurotrophic factor (GDNF), ${ }^{161}$ and tyrosine hydroxylase. ${ }^{162}$ There is evidence that GDNF levels are reduced in depressive disorders ${ }^{163,164}$ and that increased GDNF-release constitutes an antidepressant mechanism. ${ }^{165}$ GDNF further promotes dopaminergic neuron survival; ${ }^{166}$ these neurons are involved in mediating depressive symptomatology. ${ }^{167-169}$ A reduction of striatal dopamine-transporter binding is observed in seasonal affective disorder, ${ }^{170}$ and dopamine seems to play a role in the semiology of this disorder. ${ }^{171}$ These findings of improved dopaminergic neuron survival ${ }^{166}$ and increases in tyrosine hydroxylase seen with MT stimulation ${ }^{162}$ suggest protective and trophic effects on mood-related dopamine neurons. $\mathrm{MT}_{1}$ effects on clock genes have also been suggested to participate in the pathobiology of mood- and dopamine-related behaviors. ${ }^{172} \mathrm{MT}_{1}$ stimulation down-regulates Clock and up-regulates neuronal PAS-domain protein 2 (NPAS2) mRNA expression in mouse striatum. ${ }^{172}$ Subjects with depression exhibit increased leukocyte clock mRNA expression. ${ }^{173}$ Several Clock $^{174-176}$ and NPAS2 ${ }^{174,177,178}$ single-nucleotide polymorphisms have been linked to $\mathrm{MDD}^{174}$ and seasonal affective disorder, ${ }^{177,178}$ as well as to bipolar depression $^{174,177,178}$ symptoms ${ }^{175}$ and recurrence. ${ }^{176}$

$\mathrm{MT}_{2}$ receptor activation inhibits NO-induced increases in cyclic $\mathrm{GMP}^{179}$ —of interest because plasma cGMP levels have been noted to be increased in patients developing depression after receiving 6 weeks of interferon treatment. ${ }^{133} \mathrm{MT}_{2}$ receptor-stimulation increases BDNF concentrations, ${ }^{156}$ induces heat-shock protein HSP27, and prevents apoptosis, ${ }^{180}$ perhaps related to agomelatine's antidepressant effect, ${ }^{115}$ since apoptotic markers are increased in depressive disorders ${ }^{113,181,182}$ and are normalized by antidepressant treatment. ${ }^{182}$

Thus, multiple effects of agomelatine over a wide range of pathophysiological processes may bring about the observed benefits in major depression, bipolar disorder, seasonal affective disorder, and generalized anxiety disorder.

A last observation regarding the mechanism(s) of action of agomelatine should be kept in mind. Agomelatine displays a similar dissociation constant $\left(\mathrm{K}_{\mathrm{d}}\right)$ for $\mathrm{MT}_{1} / \mathrm{MT}_{2}$ melatonin receptors to that of melatonin itself; that is, $10 \mathrm{nM}$ at 10 p.m. ${ }^{102}$ This fact implies that doses of $1 \mathrm{mg}-3 \mathrm{mg}$ melatonin or agomelatine are enough to saturate both $\mathrm{MT}_{1} / \mathrm{MT}_{2}$ receptors in the body. However, the therapeutic doses of agomelatine normally range between $25 \mathrm{mg}$ /day and $50 \mathrm{mg} /$ day, suggesting that an effect other than binding to $\mathrm{MT}_{1} / \mathrm{MT}_{2}$ receptors (and 5$\mathrm{HT}_{2 \mathrm{c}}$ receptors) might take place. In this regard, it was recently reported that melatonin does not move freely through the body, as has earlier been suggested. Instead, subcellular melatonin distribution is a regulated process, even in the brain; ${ }^{183}$ so studying the intracellular distribution of agomelatine may yield important information regarding intracellular effects of this melatonin analog.

\section{CONCLUSIONS}

Agomelatine, the melatonergic agonist, has demonstrated its antidepressant effect in a number of preclinical studies undertaken on animal models of depression. It has also demonstrated its potency in resynchronizing disturbed circadian rhythms in experimental animals, and this effect is attributed to agomelatine's actions on melatonergic receptors in the suprachiasmatic nucleus. In more than 11 clinical studies undertaken in Europe, involving a large number of patients from different centers, agomelatine has been found to be effective in reducing depressive symptoms, improving sleep quality and efficiency, and re-setting the disturbed circadian rhythm. Unlike the other antidepressants, agomelatine exhibited sleep and antidepressant effects within a week of its administration. In a number of studies, agomelatine's clinical efficacy was sustained 
through 24 weeks of administration without any adverse side effects. Treatment of depressive disorders, MDD, bipolar I disorder, SAD, and GAD was not associated with co-prescription of hypnotic-sedatives. A recent review summarized the clinical efficacy of agomelatine in various depressive symptoms, such as 1) core symptoms; 2) sleep symptoms; 3) anxiety; 4) retardation; 5) somatic symptoms; 6) anxiety; and 7) work and alertness. Moreover, agomelatine has been shown to be efficient in severe depression. ${ }^{184}$ The mechanism of agomelatine's antidepressant effect is attributed to its actions on melatonergic receptors $\left(\mathrm{MT}_{1} / \mathrm{MT}_{2}\right)$ present in the $\mathrm{SCN}$, as well as to its $5-\mathrm{HT}_{2 \mathrm{C}}$ antagonism. By improving sleep and resynchronizing disrupted circadian rhythms, agomelatine exerts its novel mode of antidepressant action. Moreover, as demonstrated by preclinical studies, agomelatine's antidepressant effect is attributed to its neurogenic effects in the dorsal and ventral hippocampal regions. Although this effect is shared by other antidepressants, such as SSRIs, agomelatine alone has a rapid effect on neurogenesis. On the basis of all available clinical studies, we can conclude that agomelatine is an effective antidepressant with a rapid onset of action not only in MDD patients in general, but also in patients with severe MDD, bipolar I disorder, $\mathrm{SAD}$, and generalized anxiety disorder. Unlike other antidepressants, agomelatine does not cause worsening of sleep disturbances or sexual dysfunction and is associated with fewer side effects than are seen with placebo therapy.

\section{References}

1. Srinivasan V, Smits M, Spence WD, et al: Melatonin in mood disorders. World J Biol Psychiatry 2006; 7:138-151

2. Bunney WE Jr, Murphy DL, Goodwin FK, et al: The switch process from depression to mania: relationship to drugs which alter brain amines. Lancet 1970; 1:1022-1027

3. Sonntag A, Rothe B, Guldner J, et al: Trimipramine and imipramine exert different effects on the sleep EEG and on nocturnal hormone secretion during treatment of major depression. Depression 1996; 4:1-13

4. Venkoba Rao A, Parvathi Devi S, Srinivasan V: Urinary melatonin in depression. Int J Psychiatry 1983; 25:167-172

5. Celada P, Puig M, Amargós-Bosch M, et al: The therapeutic role of 5-HT1A and 5-HT2A receptors in depression. J Psychiatry Neurosci 2004; 29:252-265

6. Ohayon MM, Roth T: Place of chronic insomnia in the course of depressive and anxiety disorders. J Psychiatr Res 2003; 37:9-15

7. Haimov I, Laudon M, Zisapel N, et al: Sleep disorders and melatonin rhythms in elderly people. BMJ 1994; 309:167

8. Rodenbeck A, Huether G, Rüther E, et al: Altered circadian melatonin secretion patterns in relation to sleep in patients with chronic sleep-wake rhythm disorders. J Pineal Res 1998; 25:201-210

9. Leger D, Laudon M, Zisapel N: Nocturnal 6-sulfatoxymelatonin excretion in insomnia and its relation to the response to melatonin replacement therapy. Am J Med 2004; 116:91-95

10. Dolberg OT, Hirschmann S, Grunhaus L: Melatonin for the treatment of sleep disturbances in major depressive disorder. Am J Psychiatry 1998; 155:1119-1121

11. Millan MJ, Gobert A, Lejeune E, et al: The novel melatonin agonist agomelatine (S20098) is an antagonist at 5-hydroxytryptamine $2 \mathrm{c}$ receptors, blockade of which enhances the activity of frontocortical dopaminergic and adrenergic pathways. Pharmacol Exp Ther 2003; 306:954-964

12. Bertaina-Anglade V, Mocaer E, Drieu La Rochelle C: Antidepressant-like action of S-20098 (agomelatine) in the learned helplessness test. Int J Neuropsychopharmacol 2002; 5(suppl1):S65

13. Goodwin GM, Emsley R, Rembry S, et al; Agomelatine Study Group: Agomelatine prevents relapse in patients with major depressive disorder without evidence of a discontinuation syndrome: a 24-week randomized, doubleblind, placebo-controlled trial. J Clin Psychiatry 2009; 70:1128-1137

14. Loo H, Hale A: D' haenen H: Determination of the dose of agomelatine, a melatonergic agonist and selective 5-HT (2C) antagonist, in the treatment of major depressive disorder: a placebo-controlled dose range study. Psychopharmacology (Berl) 2002; 17:239-247

15. Kennedy SH, Emsley R: Placebo-controlled trial of agomelatine in the treatment of major depressive disorder. Eur Neuropsychopharmacol 2006; 16:93-100

16. Pandi-Perumal SR, Srinivasan V, Cardinali DP, et al: Could agomelatine be the ideal antidepressant? Expert Rev Neurother 2006; 6:1595-1608

17. Cardinali DP, Pandi-Perumal SR, Srinivasan V, et al: Therapeutic potential of melatonin agonists. Expert Rev Endocrinol Metab 2008; 3:269-279

18. Klein DC, Weller JL, Moore RY: Melatonin metabolism: neural regulation of pineal serotonin: acetyl coenzyme A Nacetyltransferase activity. Proc Natl Acad Sci USA 1971; 68:3107-3110

19. Cardinali DP, Rosner JM: Metabolism of serotonin by the rat retina in vitro. J Neurochem 1971; 18:1769-1770

20. Bubenik GA: Gastrointestinal melatonin: localization, function, and clinical relevance. Dig Dis Sci 2002; 47:2336-2348

21. Slominski A, Fischer TW, Zmijewski MA, et al: On the role of melatonin in skin physiology and pathology. Endocrine 2005, 27:137-148

22. Carrillo-Vico A, Calvo JR, Abreu P, et al: Evidence of melatonin synthesis by human lymphocytes and its physiological significance: possible role as intracrine, autocrine, and/or paracrine substance. FASEB J 2004; 18:537-539

23. Naranjo MC, Guerrero JM, Rubio A, et al: Melatonin biosynthesis in the thymus of humans and rats. Cell Mol Life Sci 2007; 64:781-790 
24. Tricoire H, Møller M, Chemineau $P$, et al: Origin of cerebrospinal fluid melatonin and possible function in the integration of photoperiod. Reprod Suppl 2003; 61:311-321

25. Claustrat B, Brun J, Chazot G: The basic physiology and pathophysiology of melatonin. Sleep Med Rev 2005; 9:11-24

26. Hirata F, Hayaishi O, Tokuyama T, et al: In-vitro and in-vivo formation of two new metabolites of melatonin. J Biol Chem 1974; 249:1311-1313

27. Reppert SM, Weaver DR, Ebisawa T: Cloning and characterization of a mammalian melatonin receptor that mediates reproductive and circadian responses. Neuron 1994; 13:1177-1185

28. Reppert SM, Godson C, Mahle CD, et al: Molecular characterization of a second melatonin receptor expressed in human retina and brain: the Mel1b melatonin receptor. Proc Natl Acad Sci USA 1995; 92:8734-8738

29. Brydon L, Roka F, Petit L, et al: Dual signaling of human Mel1a melatonin receptors via G(i2), G(i3), and G(q/11) proteins. Mol Endocrinol 1999; 13:2025-2038

30. Boutin JA, Audinot V, Ferry G, et al: Molecular tools to study melatonin pathways and actions. Trends Pharmacol Sci 2005; 26:412-419

31. Srinivasan V, Pandi-Perumal SR, Trahkt I, et al: Melatonin and melatonergic drugs on sleep: possible mechanisms of action. Int J Neurosci 2009; 119:821-846

32. Kupfer DJ, Spiker DG, Coble PA, et al: Sleep and treatment prediction in endogenous depression. Am J Psychiatry 1981; 138:429-434

33. Riemann D, Berger M, Voderholzer U: Sleep and depression: a challenge for anti-depresaants, an overview. Biol Psychol 2001; 57:67-103

34. Armitage R: Sleep and circadian rhythms in mood disorders. Acta Psychiatr Scand Suppl 2007; (433):104-115

35. Ford DE, Kamerow DB: Epidemiologic study of sleep disturbances and psychiatric disorders. An opportunity for prevention? JAMA 1989; 262:1479-1484

36. Lam RW: Sleep disturbances and depression: a challenge for antidepressants. Int Clin Psychopharmacol 2006; 21(Suppl 1): S25-S29

37. Lustberg L, Reynolds CF: Depression and insomnia: questions of cause and effect. Sleep Med Rev 2000; 4:253-262

38. Pandi-Perumal SR, Moscovitch A, Srinivasan V, et al: Bidirectional communication between sleep and circadian rhythms and its implications for depression: lessons from agomelatine. Prog Neurobiol 2009; 88:264-271

39. Srinivasan V, Brzezinski A, Spence DW, et al: Sleep, mood disorders and antidepressants: the melatonergic anti-depressant agomelatine offers a new strategy of treatment. Psychiatr Fenn 2010; 41:168-187

40. Kupfer DJ: Depression and associated sleep disturbances: patient's benefits with agomelatine. Eur Neuropsychopharmacol 2006; 16(suppl5): S 639-S643

41. Thase ME: Pharmacotherapy of bipolar depression: an update. Curr Psychiatry Rep 2006; 8:478-488

42. Ruhé HG, Mason NS, Schene AH: Mood is indirectly related to serotonin, norepinephrine and dopamine levels in humans: a meta-analysis of monoamine depletion studies. Mol Psychiatry 2007; 12:331-359

43. Rouillon F: Efficacy and tolerance profile of agomelatine and practical use in depressed patients. Int Clin Psychopharmacol 2006; 21(Suppl 1):S31-S35
44. Yous S, Andrieux J, Howell HE, et al: Novel naphthalenic ligands with high affinity for the melatonin receptor. J Med Chem 1992; 35:1484-1486

45. Bogaards JJ, Hissink EM, Briggs M, et al: Prediction of interindividual variation in drug plasma levels in vivo from individual enzyme kinetic data and physiologically based pharmacokinetic modeling. Eur J Pharm Sci 2000; 12:117-124

46. Pepin MC, Pothier F, Barden N: Antidepressant drug action in a transgenic mouse model of the endocrine changes seen in depression. Mol Pharmacol 1992; 42:991-995

47. Chagraoui A, Protais P, Filloux T, et al: Agomelatine(S 20098) antagonizes the penile erections induced by the stimulation of 5-HT2C receptors in Wistar rats. Psychopharmacology (Berl) 2003; 170:17-22

48. Giorgetti M, Tecott LH: Contributions of 5-HT(2C) receptors to multiple actions of central serotonin systems. Eur J Pharmacol 2004; 488:1-9

49. Bourin M, Mocaër E, Porsolt R: Antidepressant-like activity of S 20098 (agomelatine) in the forced swimming test in rodents: involvement of melatonin and serotonin receptors. J Psychiatry Neurosci 2004; 29:126-133

50. Porsolt RD, Anton G, Blavet N, et al: Behavioural despair in rats: a new model sensitive to antidepressant treatments. Eur J Pharmacol 1978; 47:379-391

51. Barden N, Shink E, Labbe M, et al: Antidepressant action of agomelatine (S20098) in a transgenic mouse model. Prog Neuropsychopharmacol Biol Psychiat 2005; 29: 08-916

52. Papp M, Gruca P, Boyer PA, et al: Effect of agomelatine in the chronic mild stress model of depression in the rat. Neuropsychopharmacology 2003; 28:694-703

53. Fuchs E, Simon M, Schmelting B: Pharmacology of a new antidepressant: benefit of the implication of the melatonergic system. Int Clin Psychopharmacol 2006; 21(Suppl 1):S17-S20

54. Bertaina-Anglade V, la Rochelle CD, Boyer PA, et al: Antidepressant-like effects of agomelatine (S 20098) in the learned helplessness model. Behav Pharmacol 2006; 17:703-713

55. Redman JR, Guardiola-Lemaitre B, Brown M, et al: Dose dependent effects of S-20098, a melatonin agonist, on direction of re-entrainment of rat circadian activity rhythms. Psychopharmacology (Berl) 1995; 118:385-390

56. Armstrong SM, McNulty OM, Guardiola-Lemaitre B, et al: Successful use of S20098 and melatonin in an animal model of delayed sleep-phase syndrome (DSPS). Pharmacol Biochem Behav 1993; 46:45-49

57. Martinet L, Guardiola-Lemaitre B, Mocaer E: Entrainment of circadian rhythms by S-20098, a melatonin agonist, is dose and plasma concentration dependent. Pharmacol Biochem Behav 1996; 54:713-718

58. Redman JR, Francis AJ: Entrainment of rat circadian rhythms by the melatonin agonist S-20098 requires intact suprachiasmatic nuclei but not the pineal. J Biol Rhythms 1998; 13:39-51

59. Pitrosky B, Kirsch R, Malan A, et al: Organization of rat circadian rhythms during daily infusion of melatonin or S20098, a melatonin agonist. Am J Physiol 1999; 277(3 Pt 2): R812-R828

60. Weibel L, Turek FW, Mocaer E, et al: A melatonin agonist facilitates circadian resynchronization in old hamsters after abrupt shifts in the light-dark cycle. Brain Res 2000; 880:207-211 
61. Leproult R, Van Onderbergen A, L'hermite-Balériaux M, et al: Phase-shifts of 24-hr rhythms of hormonal release and body temperature following early evening administration of the melatonin agonist agomelatine in healthy older men. Clin Endocrinol (Oxf) 2005; 63:298-304

62. Fuchs E: Social stress in tree shrews as an animal model of depression: an example of a behavioral model of a CNS disorder. CNS Spectr 2005; 10:182-190

63. Loiseau F, Le Bihan C, Hamon M, et al: Effects of melatonin and agomelatine in anxiety-related procedures in rats: interaction with diazepam. Eur Neuropsychopharmacol 2006; 16:417-428

64. Rainer Q, Xia L, Guilloux JP, et al: Beneficial behavioural and neurogenic effects of agomelatine in a model of depression/ anxiety. Int J Neuropsychopharmacol 2011; 8:1-15

65. Bannerman DM, Deacon RM, Brady S, et al: A comparison of GluR-A-deficient and wild-type mice on a test battery assessing sensorimotor, affective, and cognitive behaviors. Behav Neurosci 2004; 118:643-647

66. Fanselow MS, Dong HW: Are the dorsal and ventral hippocampus functionally distinct structures? Neuron 2010; 65:7-19

67. Lemoine P, Guilleminault C, Alvarez E: Improvement in subjective sleep in major depressive disorder with a novel antidepressant, agomelatine: randomized, double-blind comparison with venlafaxine. J Clin Psychiatry 2007; 68: 1723-1732

68. Kennedy SH, Lam RW, Cohen NL, et al; CANMAT Depression Work Group: Clinical guidelines for the treatment of depressive disorders. IV. Medications and other biological treatments. Can J Psychiatry 2001; 46(Suppl 1):38S-58S

69. Clerc G; Milnacipran/Fluvoxamine Study Group: Antidepressant efficacy and tolerability of milnacipran, a dual serotonin and noradrenaline reuptake inhibitor: a comparison with fluvoxamine. Int Clin Psychopharmacol 2001; 16:145151

70. Kennedy SH, Rizvi S, Fulton K, et al: A double-blind comparison of sexual functioning, antidepressant efficacy, and tolerability between agomelatine and venlafaxine XR. J Clin Psychopharmacol 2008; 28:329-333

71. Di Giannantonio M, Di Iorio G, Guglielmo R, et al: Major depressive disorder, anhedonia and agomelatine: an openlabel study. J Biol Regul Homeost Agents 2011; 25:109-114

72. Calabrese JR, Guelfi JD, Perdrizet-Chevallier C: Agomelatine Bipolar Study Group: Agomelatine adjunctive therapy for acute bipolar depression: preliminary open data. Bipolar Disord 2007; 9:628-635

73. Pjrek E, Winkler D, Konstantinidis A, et al: Agomelatine in the treatment of seasonal affective disorder. Psychopharmacology (Berl) 2007; 190:575-579

74. Fornaro M, Prestia D, Colicchio S, et al: A systematic, updated review on the antidepressant agomelatine focusing on its melatonergic modulation. Curr Neuropharmacol 2010; 8:287-304

75. Stein DJ, Ahokas AA, de Bodinat C: Efficacy of agomelatine in generalized anxiety disorder: a randomized, double-blind, placebo-controlled study. J Clin Psychopharmacol 2008; 28:561-566

76. Tabeeva GR, Sergeev AV, Gromova SA: [Possibilities of preventive treatment of migraine with the MT1- and MT2 agonist and 5-HT2c receptor antagonist agomelatin (valdoxan)]. Zh Nevrol Psikhiatr Im S S Korsakova 2011; 111:32-36

77. Fibrose T, Skwik FI, Schreiner R, et al: Agomelatine improves sleep in patient with Fatal Familial Insomnia. Pharmacopsychiatry 2011; 45(1):34-36

78. Kennedy SH, Rizvi SJ: Agomelatine in the treatment of major depressive disorder: potential for clinical effectiveness. CNS Drugs 2010; 24:479-499

79. Rosen RC, Lane RM, Menza M: Effects of SSRIs on sexual function: a critical review. J Clin Psychopharmacol 1999; 19:67-85

80. Kennedy SH: Sexual function in remitted depresse patient following agomelatine. Eur Neuropsychopharmacol 2005; 15 (Supp. 3):S440

81. Dubocovitch ML: Agomelatine targets a range of major depressive disorder symptoms. Curr Opin Invest drugs 2006; 7: 670-680

82. Varcoe TJ, Kennaway DJ: Activation of 5-HT2C receptors acutely induces Per1 gene expression in the rat SCN in vitro. Brain Res 2008; 1209:19-28

83. Martin JR, Bös M, Jenck F, et al: 5-HT2C receptor agonists: pharmacological characteristics and therapeutic potential. J Pharmacol Exp Ther 1998; 286:913-924

84. Lader M: Limitations of current medical treatments for depression: disturbed circadian rhythms as a possible therapeutic target. Eur Neuropsychopharmacol 2007; 17:743755

85. Racagni G, Riva MA, Popoli M: The interaction between the internal clock and antidepressant efficacy. Int Clin Psychopharmacol 2007; 22(Suppl 2):S9-S14

86. Quera-Salva MA, Lemoine P, Guilleminault C: Impact of the novel antidepressant agomelatine on disturbed sleep-wake cycles in depressed patients. Hum Psychopharmacol 2010; 25:222-229

87. McClung CA: Circadian genes, rhythms and the biology of mood disorders. Pharmacol Ther 2007; 114:222-232

88. Guilding C, Piggins HD: Challenging the omnipotence of the suprachiasmatic timekeeper: are circadian oscillators present throughout the mammalian brain? Eur J Neurosci 2007; 25:3195-3216

89. Czeisler CA, Duffy JF, Shanahan TL, et al: Stability, precision, and near-24-hour period of the human circadian pacemaker. Science 1999; 284:2177-2181

90. Rusak B, Zucker I: Neural regulation of circadian rhythms. Physiol Rev 1979; 59:449-526

91. Akerstedt T: Altered sleep/wake patterns and mental performance. Physiol Behav 2007; 90:209-218

92. Waterhouse J, Minors D, Akerstedt T, et al: Circadian rhythm adjustment: difficulties in assessment caused by masking. Pathol Biol (Paris) 1996; 44:205-207

93. Liu C, Weaver DR, Jin X, et al: Molecular dissection of two distinct actions of melatonin on the suprachiasmatic circadian clock. Neuron 1997; 19:91-102

94. Jin X, von Gall C, Pieschl RL, et al: Targeted disruption of the mouse $\operatorname{Mel}(1 b)$ melatonin receptor. Mol Cell Biol 2003; 23:1054-1060

95. Srinivasan V, Pandi-Perumal SR, Trakht I, et al: Pathophysiology of depression: role of sleep and the melatonergic system. Psychiatry Res 2009; 165:201-214 
96. Eser D, Baghai TC, Möller HJ: Evidence of agomelatine's antidepressant efficacy: the key points. Int Clin Psychopharmacol 2007; 22(Suppl 2):S15-S19

97. De Berardis D, Di Iorio G, Acciavatti T, et al: The emerging role of melatonin agonists in the treatment of major depression: focus on agomelatine. CNS Neurol Disord Drug Targets 2011; 10:119-132

98. Llorca PM: The antidepressant agomelatine improves the quality of life of depressed patients: implications for remission. J Psychopharmacol 2010; 24(Suppl):21-26

99. Srinivasan V, Cardinali DP, Pandi-Perumal SR, et al: Melatonin agonists for treatment of sleep and depressive disorders. J Exptl Integ Med 2011; 1:149-158

100. Kennedy SH, Young AH, Blier P: Strategies to achieve clinical effectiveness: refining existing therapies and pursuing emerging targets. J Affect Disord 2011; 132(Suppl 1):S21-S28

101. Kennedy SH, Rizvi SJ: Emerging drugs for major depressive disorder. Expert Opin Emerg Drugs 2009; 14:439-453

102. de Bodinat C, Guardiola-Lemaitre B, Mocaër E, et al: Agomelatine, the first melatonergic antidepressant: discovery, characterization and development. Nat Rev Drug Discov 2010; 9:628-642

103. Banasr M, Soumier A, Hery M, et al: Agomelatine, a new antidepressant, induces regional changes in hippocampal neurogenesis. Biol Psychiatry 2006; 59:1087-1096

104. Soumier A, Banasr M, Lortet S, et al: Mechanisms contributing to the phase-dependent regulation of neurogenesis by the novel antidepressant, agomelatine, in the adult rat hippocampus. Neuropsychopharmacology 2009; 34:2390-2403

105. Païzanis E, Renoir T, Lelievre V, et al: Behavioural and neuroplastic effects of the new-generation antidepressant agomelatine compared to fluoxetine in glucocorticoid receptorimpaired mice. Int J Neuropsychopharmacol 2010; 13:759774

106. Moser MB, Moser EI: Functional differentiation in the hippocampus. Hippocampus 1998; 8:608-619

107. Wang JW, David DJ, Monckton JE, et al: Chronic fluoxetine stimulates maturation and synaptic plasticity of adult-born hippocampal granule cells. J Neurosci 2008; 28:1374-1384

108. Engin E, Treit D: The role of hippocampus in anxiety: intracerebral infusion studies. Behav Pharmacol 2007; 18:365374

109. Kasper S, Hajak G, Wulff K, et al: Efficacy of the novel antidepressant agomelatine on the circadian rest-activity cycle and depressive and anxiety symptoms in patients with major depressive disorder: a randomized, double-blind comparison with sertraline. J Clin Psychiatry 2010; 71:109-120

110. Kumar A, Singh A: Protective effect of St. John's wort (Hypericum perforatum) extract on 72-hour sleep deprivation-induced anxiety-like behavior and oxidative damage in mice. Planta Med 2007; 73:1358-1364

111. Cirelli C, Tononi G: Uncoupling proteins and sleep deprivation. Arch Ital Biol 2004; 142:541-549

112. Cirelli C, Faraguna U, Tononi G: Changes in brain gene expression after long-term sleep deprivation. J Neurochem 2006; 98:1632-1645

113. Szuster-Ciesielska A, Słotwińska M, Stachura A, et al: Accelerated apoptosis of blood leukocytes and oxidative stress in blood of patients with major depression. Prog Neuropsychopharmacol Biol Psychiatry 2008; 32:686-694
114. Andreazza AC, Shao L, Wang JF, et al: Mitochondrial complex I activity and oxidative damage to mitochondrial proteins in the prefrontal cortex of patients with bipolar disorder. Arch Gen Psychiatry 2010; 67:360-368

115. Shelton RC, Claiborne J, Sidoryk-Wegrzynowicz M, et al: Altered expression of genes involved in inflammation and apoptosis in frontal cortex in major depression. Mol Psychiatry $2011 ; 16: 751-762$

116. Maes M, Ruckoanich P, Chang YS, et al: Multiple aberrations in shared inflammatory and oxidative \& nitrosative stress (IO\&NS) pathways explain the co-association of depression and cardiovascular disorder (CVD), and the increased risk for CVD and due mortality in depressed patients. Prog Neuropsychopharmacol Biol Psychiatry 2011; 35:769-783

117. Che Y, Wang JF, Shao L, et al: Oxidative damage to RNA but not DNA in the hippocampus of patients with major mental illness. J Psychiatry Neurosci 2010; 35:296-302

118. Oh DH, Park YC, Kim SH: Increased glycogen synthase kinase- $3 \beta$ mRNA level in the hippocampus of patients with major depression: a study using the stanley neuropathology consortium integrative database. Psychiatry Investig 2010; 7:202-207

119. Andreazza AC, Kauer-Sant'anna M, Frey BN, et al: Oxidative stress markers in bipolar disorder: a meta-analysis. J Affect Disord 2008; 111:135-144

120. Kunz M, Gama CS, Andreazza AC, et al: Elevated serum superoxide dismutase and thiobarbituric acid reactive substances in different phases of bipolar disorder and in schizophrenia. Prog Neuropsychopharmacol Biol Psychiatry 2008; 32:1677-1681

121. Wang JF, Shao L, Sun X, et al: Increased oxidative stress in the anterior cingulate cortex of subjects with bipolar disorder and schizophrenia. Bipolar Disord 2009; 11:523-529

122. Clay HB, Sillivan S, Konradi C: Mitochondrial dysfunction and pathology in bipolar disorder and schizophrenia. Int J Dev Neurosci 2011; 29:311-324

123. Selek S, Altindag A, Saracoglu G, et al: Prolidase activity and its diagnostic performance in bipolar disorder. J Affect Disord 2011; 129:84-86

124. Ross BM, Maxwell R, Glen I: Increased breath ethane levels in medicated patients with schizophrenia and bipolar disorder are unrelated to erythrocyte omega-3 fatty acid abundance. Prog Neuropsychopharmacol Biol Psychiatry 2011; 35:446-453

125. Gigante AD, Young LT, Yatham LN, et al: Morphometric post-mortem studies in bipolar disorder: possible association with oxidative stress and apoptosis. Int J Neuropsychopharmacol 2011; 14:1075-1089

126. Atmaca M, Tezcan E, Kuloglu M, et al: Antioxidant enzyme and malondialdehyde values in social phobia before and after citalopram treatment. Eur Arch Psychiatry Clin Neurosci 2004; 254:231-235

127. Hovatta I, Tennant RS, Helton R, et al: Glyoxalase 1 and glutathione reductase 1 regulate anxiety in mice. Nature 2005; 438:662-666

128. Rammal H, Bouayed J, Younos C, et al: The impact of high anxiety level on the oxidative status of mouse peripheral blood lymphocytes, granulocytes, and monocytes. Eur J Pharmacol 2008; 589:173-175

129. Modica-Napolitano JS, Renshaw PF: Ethanolamine and phosphoethanolamine inhibit mitochondrial function in vitro: 
implications for mitochondrial dysfunction hypothesis in depression and bipolar disorder. Biol Psychiatry 2004; 55:273-277

130. Fattal O, Link J, Quinn K, et al: Psychiatric comorbidity in 36 adults with mitochondrial cytopathies. CNS Spectr 2007; 12:429-438

131. Gardner A, Boles RG: Beyond the serotonin hypothesis: mitochondria, inflammation and neurodegeneration in major depression and affective spectrum disorders. Prog Neuropsychopharmacol Biol Psychiatry 2011; 35:730-743

132. Konradi C, Sillivan SE, Clay HB: Mitochondria, oligodendrocytes, and inflammation in bipolar disorder: evidence from transcriptome studies points to intriguing parallels with multiple sclerosis. Neurobiol Dis 2012; 45(1):37-47

133. Kagaya A, Uchitomi Y, Takezaki E, et al: Plasma levels of cyclic GMP, immune parameters and depressive status during interferon therapy. A prospective study in Japan. Neuropsychobiology 1997; 35:128-131

134. Song C, Wang H: Cytokines-mediated inflammation and decreased neurogenesis in animal models of depression. Prog Neuropsychopharmacol Biol Psychiatry 2011; 35:760-768

135. Hashioka S: Antidepressants and neuroinflammation: can antidepressants calm glial rage down? Mini Rev Med Chem 2011; 11:555-564

136. Rao JS, Harry GJ, Rapoport SI, et al: Increased excitotoxicity and neuroinflammatory markers in postmortem frontal cortex from bipolar disorder patients. Mol Psychiatry 2010; 15:384392

137. Kim HW, Rapoport SI, Rao JS: Altered expression of apoptotic factors and synaptic markers in postmortem brain from bipolar disorder patients. Neurobiol Dis 2010; 37:596-603

138. Duncan RE, Bazinet RP: Brain arachidonic acid uptake and turnover: implications for signaling and bipolar disorder. Curr Opin Clin Nutr Metab Care 2010; 13:130-138

139. Drew JE, Barrett P, Mercer JG, et al: Localization of the melatonin-related receptor in the rodent brain and peripheral tissues. J Neuroendocrinol 2001; 13:453-458

140. Wiechmann AF, Wirsig-Wiechmann CR: Melatonin receptor distribution in the brain and retina of a lizard, Anolis carolinensis. Brain Behav Evol 1994; 43:26-33

141. Stankov B, Cozzi B, Lucini V, et al: Localization and characterization of melatonin binding sites in the brain of the rabbit (Oryctolagus cuniculus) by autoradiography and in vitro ligand-receptor binding. Neurosci Lett 1991; 133:68-72

142. Al-Ghoul WM, Herman MD, Dubocovich ML: Melatonin receptor subtype expression in human cerebellum. Neuroreport 1998; 9:4063-4068

143. Savaskan E, Ayoub MA, Ravid R, et al: Reduced hippocampal MT2 melatonin receptor expression in Alzheimer's disease. J Pineal Res 2005; 38:10-16

144. Das A, Belagodu A, Reiter RJ, et al: Cytoprotective effects of melatonin on C6 astroglial cells exposed to glutamate excitotoxicity and oxidative stress. J Pineal Res 2008; 45:117124

145. Caballero B, Vega-Naredo I, Sierra V, et al: Favorable effects of a prolonged treatment with melatonin on the level of oxidative damage and neurodegeneration in senescenceaccelerated mice. J Pineal Res 2008; 45:302-311

146. Das A, McDowell M, Pava MJ, et al: The inhibition of apoptosis by melatonin in VSC4.1 motoneurons exposed to oxidative stress, glutamate excitotoxicity, or TNF-alpha toxicity involves membrane melatonin receptors. J Pineal Res 2010; 48:157-169

147. Choi SI, Dadakhujaev S, Ryu H, et al: Melatonin protects against oxidative stress in granular corneal dystrophy type 2 corneal fibroblasts by mechanisms that involve membrane melatonin receptors. J Pineal Res 2011; 51:94-103

148. Dhir A, Kulkarni SK: Nitric oxide and major depression. Nitric Oxide 2011; 24:125-131

149. Selek S, Savas HA, Gergerlioglu HS, et al: The course of nitric oxide and superoxide dismutase during treatment of bipolar depressive episode. J Affect Disord 2008; 107:89-94

150. Storr M, Koppitz P, Sibaev A, et al: Melatonin reduces nonadrenergic, non-cholinergic relaxant neurotransmission by inhibition of nitric oxide synthase activity in the gastrointestinal tract of rodents in vitro. J Pineal Res 2002; 33: 101-108

151. Castrén E, Rantamäki T: The role of BDNF and its receptors in depression and antidepressant drug action: Reactivation of developmental plasticity. Dev Neurobiol 2010; 70:289-297

152. Hashimoto K: Brain-derived neurotrophic factor as a biomarker for mood disorders: an historical overview and future directions. Psychiatry Clin Neurosci 2010; 64:341-357

153. Yu H, Chen ZY: The role of BDNF in depression on the basis of its location in the neural circuitry. Acta Pharmacol Sin 2011; 32:3-11

154. Grande I, Fries GR, Kunz M, et al: The role of BDNF as a mediator of neuroplasticity in bipolar disorder. Psychiatry Investig 2010; 7:243-250

155. Fernandes BS, Gama CS, Ceresér KM, et al: Brain-derived neurotrophic factor as a state-marker of mood episodes in bipolar disorders: a systematic review and meta-regression analysis. J Psychiatr Res 2011; 45:995-1004

156. Imbesi M, Uz T, Dzitoyeva S, et al: Stimulatory effects of a melatonin receptor agonist, ramelteon, on BDNF in mouse cerebellar granule cells. Neurosci Lett 2008; 439:34-36

157. Molteni R, Calabrese F, Pisoni S, et al: Synergistic mechanisms in the modulation of the neurotrophin BDNF in the rat prefrontal cortex following acute agomelatine administration. World J Biol Psychiatry 2010; 11:148-153

158. Peschke E, Mühlbauer E, Musshoff U, et al: Receptor (MT(1)) mediated influence of melatonin on cAMP concentration and insulin secretion of rat insulinoma cells INS-1. J Pineal Res 2002; 33:63-71

159. Lerer B, Ebstein RP, Belmaker RH: Subsensitivity of human beta-adrenergic adenylate cyclase after salbutamol treatment of depression. Psychopharmacology (Berl) 1981; 75:169-172

160. Reierson GW, Mastronardi CA, Licinio J, et al: Chronic imipramine downregulates cyclic AMP signaling in rat hippocampus. Neuroreport 2009; 20:307-311

161. Castro LM, Gallant M, Niles LP: Novel targets for valproic acid: up-regulation of melatonin receptors and neurotrophic factors in C6 glioma cells. J Neurochem 2005; 95:1227-1236

162. Kong X, Li X, Cai Z, et al: Melatonin regulates the viability and differentiation of rat midbrain neural stem cells. Cell Mol Neurobiol 2008; 28:569-579

163. Michel TM, Frangou S, Camara S, et al: Altered glial cell linederived neurotrophic factor (GDNF) concentrations in the brain of patients with depressive disorder: a comparative post-mortem study. Eur Psychiatry 2008; 23:413-420 
164. Wang X, Hou Z, Yuan Y, et al: Association study between plasma GDNF and cognitive function in late-onset depression. J Affect Disord 2011; 132:418-421

165. Di Benedetto B, Kühn R, Nothdurfter C, et al: Ndesalkylquetiapine activates ERK1/2 to induce GDNF release in C6 glioma cells: A putative cellular mechanism for quetiapine as antidepressant. Neuropharmacology 2012; 62(1):209-216

166. Niles LP, Armstrong KJ, Rincón Castro LM, et al: Neural stem cells express melatonin receptors and neurotrophic factors: colocalization of the MT1 receptor with neuronal and glial markers. BMC Neurosci 2004; 5:41

167. Willner P: Dopamine and depression: a review of recent evidence. I. Empirical studies. Brain Res 1983; 287:211-224

168. Dailly E, Chenu F, Renard CE, et al: Dopamine, depression and antidepressants. Fundam Clin Pharmacol 2004; 18:601607

169. Nestler EJ, Carlezon WA Jr: The mesolimbic dopamine reward circuit in depression. Biol Psychiatry 2006; 59:1151-1159

170. Neumeister A, Willeit M, Praschak-Rieder N, et al: Dopamine transporter availability in symptomatic depressed patients with seasonal affective disorder and healthy controls. Psychol Med 2001; 31:1467-1473

171. Partonen T: Dopamine and circadian rhythms in seasonal affective disorder. Med Hypotheses 1996; 47:191-192

172. Imbesi M, Arslan AD, Yildiz S, et al: The melatonin receptor MT1 is required for the differential regulatory actions of melatonin on neuronal 'clock' gene expression in striatal neurons in vitro. J Pineal Res 2009; 46:87-94

173. Gouin JP, Connors J, Kiecolt-Glaser JK, et al: Altered expression of circadian rhythm genes among individuals with a history of depression. J Affect Disord 2010; 126:161166

174. Soria V, Martínez-Amorós E, Escaramís G, et al: Differential association of circadian genes with mood disorders: CRY1 and NPAS2 are associated with unipolar major depression and CLOCK and VIP with bipolar disorder. Neuropsychopharmacology 2010; 35:1279-1289

175. Benedetti F, Dallaspezia S, Fulgosi MC, et al: Actimetric evidence that CLOCK 3111 T/C SNP influences sleep and activity patterns in patients affected by bipolar depression. Am J Med Genet B Neuropsychiatr Genet 2007; 144B:631-635

176. Benedetti F, Serretti A, Colombo C, et al: Influence of CLOCK gene polymorphism on circadian mood fluctuation and illness recurrence in bipolar depression. Am J Med Genet B Neuropsychiatr Genet 2003; 123B:23-26

177. Partonen T, Treutlein J, Alpman A, et al: Three circadian clock genes Per2, Arntl, and Npas2 contribute to winter depression. Ann Med 2007; 39:229-238

178. Johansson C, Willeit M, Smedh C, et al: Circadian clockrelated polymorphisms in seasonal affective disorder and their relevance to diurnal preference. Neuropsychopharmacology 2003; 28:734-739

179. Tunstall RR, Shukla P, Grazul-Bilska A, et al: MT2 receptors mediate the inhibitory effects of melatonin on nitric oxideinduced relaxation of porcine isolated coronary arteries. J Pharmacol Exp Ther 2011; 336:127-133

180. Cabrera J, Quintana J, Reiter RJ, et al: Melatonin prevents apoptosis and enhances HSP27 mRNA expression induced by heat shock in HL-60 cells: possible involvement of the MT2 receptor. J Pineal Res 2003; 35:231-238

181. Ivanova SA, Semke VY, Vetlugina TP, et al: Signs of apoptosis of immunocompetent cells in patients with depression. Neurosci Behav Physiol 2007; 37:527-530

182. McKernan DP, Dinan TG, Cryan JF: "Killing the Blues": a role for cellular suicide (apoptosis) in depression and the antidepressant response? Prog Neurobiol 2009; 88:246-263

183. Venegas C, García JA, Escames G, et al: Extrapineal melatonin: analysis of its subcellular distribution and daily fluctuations. J Pineal Res 2011; 52:217-227

184. Demyttenaere K: Agomelatine: a narrative review. Eur Neuropsychopharmacol 2011; 21(Suppl 4):S703-S709

185. Pjrek E, Winkler D, Konstantinidis A, et al: Agomelatine in the treatment of seasonal disorder. Psychopharmacology (Berl) 2007; 190(4):575-579

186. Olié JP, Kasper S: Efficacy of agomelatine, a MT1/MT2 receptor agonist with 5-HT2C antagonistic properties, in major depressive disorder. Int J Neuropsychopharmacol 2007; 10(5): 661-673 